\title{
Conocimiento acerca de los patógenos virales y bacterianos presentes en mamíferos silvestres en Chile: una revisión sistemática
}

\author{
Sebastián Llanos-Soto ${ }^{1,2}$ y Daniel González-Acuña ${ }^{2}$
}

\section{Knowledge about viral and bacterial pathogens present in wild mammals in Chile: a systematic review}

This study organizes all available information about viral and bacterial pathogens of wild mammals in Chile. This was done in order to identify pathogens that have been well-documented and recognize those that have not been properly studied, determine the number of articles that have been published annually about this topic and identify regions in Chile that concentrate the highest and lowest number of studies concerning viral and bacterial pathogens. A total of 67 scientific articles published in peer-reviewed journals from 1951 to 2018 were selected for revision. Results indicate that the number of publications has increased per decade but there are years in which no articles were published. Most studies addressed Leptospira, rabies, hantavirus, Mycobacterium avium paratuberculosis (MAP) and distemper. Rodentia, Carnivora, Chiroptera and Cetartiodactyla were the most studied mammal orders. Information about presence/absence of pathogens was found for 44 wild mammal species. Research was mainly carried out in central and southern Chile and the most commonly employed methods for pathogen diagnosis were serology and molecular techniques. Overall, research in Chilean wild mammals has been directed towards the evaluation of zoonotic diseases, while vector-borne and non-zoonotic diseases have been mostly neglected by the scientific community.

Keywords: bacteria; Chile; mammals; virus; zoonoses.

Palabras clave: bacteria; Chile; mamíferos; virus; zoonosis.

\section{Introducción}

$\mathrm{E}$ 1 conocimiento acerca de la presencia de enfermedades infecciosas en fauna silvestre es crucial para entender las consecuencias potenciales que éstas pueden tener en la conservación de especies silvestres y evaluar la amenaza que significan para la salud humana ${ }^{1}$. Factores antropogénicos, como la introducción de especies exóticas, el cambio climático, la fragmentación y pérdida de hábitat y la invasión humana en áreas naturales, puede incrementar el riesgo de transmisión de enfermedades desde reservorios silvestres a los animales domésticos y humanos ${ }^{2,3}$.

Las enfermedades que son transmitidas entre animales y humanos se conocen como zoonosis y causan tanto pérdidas económicas como sociales, particularmente en países no desarrollados y en vías de desarrollo ${ }^{3}$. Los patógenos zoonóticos, como los virus de la rabia, tienen su origen en reservorios mamíferos y son considerados extremadamente importantes para los sistemas de salud pública por sus consecuencias en la salud humana ${ }^{4,5}$. En este contexto, los individuos afectados pueden tener su salud afectada por enfermedades zoonóticas y, en muchos casos éstas, pueden ser erróneamente caracterizadas como enfermedades comunes o incluso no ser detectadas por las instituciones competentes ${ }^{6}$. Las actividades industriales y de urbanización, como la agricultura y actividad forestal, se han intensificado en Chile en años recientes y, probablemente, esta tendencia continúe en el futuro ${ }^{7}$. Estos factores pueden llevar a la fragmentación de hábitat, disrupción ecosistémica y sobreexplotación de especies, lo que sumado a la expansión de las poblaciones humanas y de animales domésticos en áreas cercanas a hábitats naturales, pueden contribuir a la transmisión de enfermedades infecciosas desde animales silvestres en vida libre a animales domésticos y humanos ${ }^{8-11}$.

Los objetivos de esta revisión fueron: obtener y organizar toda la información disponible en artículos publicados en revistas científicas que incluyan la determinación de infecciones virales y bacterianas en mamíferos silvestres chilenos; identificar qué patógenos han sido priorizados por la comunidad científica local y cuáles no han recibido suficiente atención; evaluar el número de artículos publicados anualmente acerca de la prevalencia de patógenos
'Laboratorio de Enfermedades y Parásitos de Fauna Silvestre. Departamento de Ciencia Animal. Facultad de Ciencias Veterinarias, Universidad de Concepción, Chile. ${ }^{2}$ Laboratorio de Vida Silvestre. Departamento de Ciencia Animal. Facultad de Ciencias Veterinarias, Universidad de Concepción, Chile.

Los autores declaran no tener conflictos de interés.

Recibido: 10 de junio de 2018 Aceptado: 25 de octubre de 2018

Correspondencia a: Daniel González Acuña danigonz@udec.cl 
virales y bacterianos en hospedadores mamíferos y reconocer el número de estudios desarrollados en este tópico en las distintas regiones de Chile.

\section{Materiales y Métodos}

La búsqueda y listado de artículos científicos revisados por pares que evalúan la presencia de patógenos virales y bacterianos en mamíferos chilenos fue realizada siguiendo las indicaciones de la declaración PRISMA (Preferred Reporting Items for Systematic Reviews and Meta-Analyses) ${ }^{12}$. Artículos publicados desde enero del año 1950 hasta julio del 2018 fueron seleccionados para revisión. Datos indicados en literatura no publicada en revistas científicas (literatura gris), fueron excluidos de este estudio (i.e., resúmenes, libros, boletines locales y presentaciones en conferencias científicas), basado en el hecho de que estos tipos de documentos científicos no experimentan un proceso riguroso de revisión por pares previo a su publicación. Esto significa que la precisión, confiabilidad y calidad de los hallazgos presentados en este tipo de documentos no puede ser asegurada. Agentes virales y bacterianos fueron considerados patógenos cuando existió información disponible en la literatura acerca de su habilidad de causar enfermedad en animales, humanos o ambos. La revisión consideró patógenos presentes en especies de mamíferos nativos e introducidos de vida libre, con la excepción de animales domésticos e individuos mantenidos en cautiverio en zoológicos, granjas y centros de exhibición. Publicaciones acerca de los patógenos presentes en mamíferos del territorio antártico chileno fueron también excluidas de este trabajo, debido ya han sido revisadas en otro artículo científico ${ }^{13}$.

Las bases de datos de Google Scholar (https://scholar. google.cl/), Scielo Scientific Library (http://www.scielo. cl/) y PubMed (https://www.ncbi.nlm.nih.gov/pubmed/) fueron utilizadas para conducir una búsqueda extensiva de publicaciones. Las siguientes palabras claves fueron ingresadas en búsquedas independientes: "bacteria", "bacteriano", "Brucella", "coronavirus", "Corynebacterium", "distémper", "enfermedad infecciosa", "hantavirus", "herpesvirus", "Leptospira", "Mycobacterium" "parvovirus", "patógeno", "Mycoplasma", "picornavirus", "rabia”, "retrovirus", "Salmonella", "vectorial”, "viral”, "virus", “zoonosis" AND "Carnivora", "Cetartiodactyla”, "Chiroptera", "Didelphimorphia", "fauna”, "Lagomorpha”, "mammal", "Microbiotheria", "Paucituberculata", "Rodentia", "Xenarthra" AND “Chile". Las mismas palabras clave fueron utilizadas para realizar búsquedas en español para incluir aquellos artículos publicados en revistas locales. Los artículos no disponibles para descarga en línea fueron buscados de forma física en las bibliotecas de la Universidad de Chile, Universidad Austral,
Pontificia Universidad Católica de Chile y Universidad de Concepción. Información acerca de la prevalencia para cada patógeno fue organizada y listada en una tabla suplementaria utilizando Microsoft Excel $^{\circledR}$ 2010. La tabla incluyó datos acerca del mamífero hospedador, caracterización del patógeno (e.g., serotipo, linaje genético, clase), región en Chile donde fue realizado el estudio y técnica utilizada para el diagnóstico. Los datos obtenidos de las publicaciones seleccionadas fueron analizados utilizando gráficos de línea para evaluar una potencial tendencia en el número de artículos publicados por década desde 1951 e identificar el orden de mamíferos más estudiado en Chile.

Los datos se obtuvieron de un total de 150 especies de mamíferos de ocho órdenes: Didelphimorphia (2), Paucituberculata (1), Microbiotheria (1), Chiroptera (11), Xenarthra (3), Rodentia (63), Cetartiodactyla (47), Lagomorpha (2) and Carnivora (20). Tres especies fueron excluidas de la revisión debido a que su distribución se encuentra restringida a la Antártica (Ommatophoca rossii) o su presencia en Chile aún no ha sido confirmada (Stenella attenuate and Stenella longirostris). Estudios de investigación que incluyeron casos previamente diagnosticados de infecciones virales y bacterianas en sus análisis (e.g., casos positivos de rabia diagnosticados por el Instituto de Salud Pública de Chile-ISP) también se incluyeron en esta revisión. Los patógenos fueron listados de mayor a menor en la discusión según el número de artículos disponibles en la literatura relacionados con dicho patógeno.

\section{Resultados}

Un total de 67 publicaciones acerca de patógenos virales y bacterianos en mamíferos chilenos fue incluido en esta revisión. De la literatura evaluada, 34 estudios investigaron la prevalencia de patógenos virales y 35 estudios se relacionaron con bacterias. Se encontró información acerca de la presencia/ausencia de patógenos para 44 especies de los órdenes Rodentia (15), Carnivora (10), Chiroptera (9), Cetartiodactyla (8), Didelphimorphia (1) y Lagomorpha (1) (Figura 1). Los detalles acerca de los resultados de esta revisión se encuentran indicados en la Tabla Suplementaria 1.

En general, el número de estudios destinados a evaluar la prevalencia de infecciones virales o bacterianas en mamíferos silvestres ha incrementado por década (Figura 2), sin embargo, durante la última década existen años en los cuales el número de artículos publicados varía entre 0 a 2 (i.e., 2010, 2012 y 2016). Las publicaciones dedicadas a cada patógeno variaron en número, pero los patógenos más estudiados fueron Leptospira (16 estudios), rabia (12 estudios), hantavirus (10 estudios), Mycobacterium avium paratuberculosis (8 estudios) y virus del distémper canino (6 estudios). 

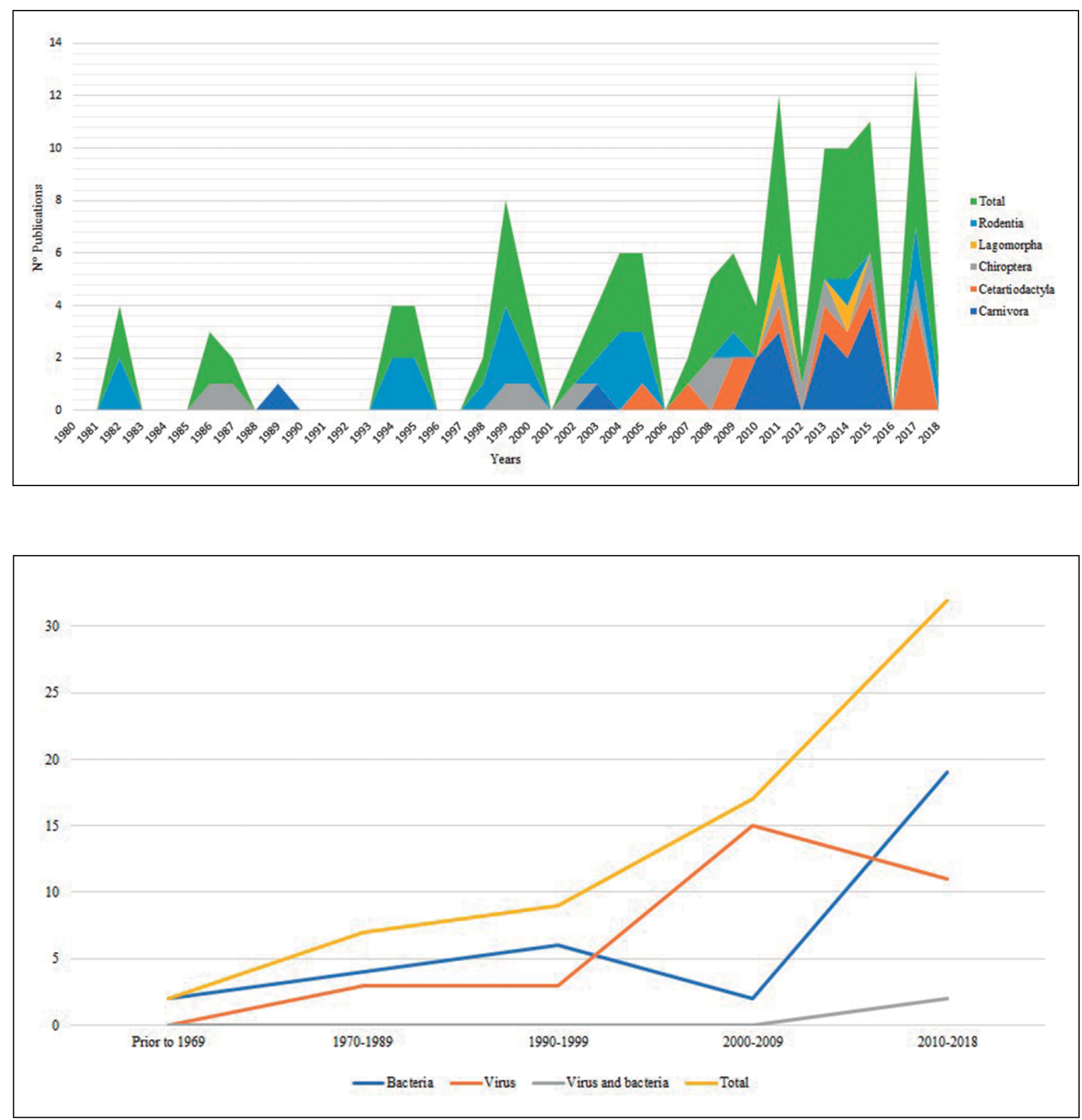

El primer estudio en registrar la presencia de patógenos en mamíferos silvestres en Chile fue realizado por Neghme y cols. en 1951 e incluyó la evaluación de Leptospira en ratas noruegas (Rattus norvegicus) capturados en un matadero de la Región Metropolitana ${ }^{14}$. Rodentia fue el orden mamífero más estudiado con 27 publicaciones destinadas a evaluar la presencia de patógenos virales y bacterianos. Un alto número de artículos se dedicaron a investigar al ratón colilargo (Oligoryzomys longicaudatus) con 19 publicaciones científicas dedicadas a evaluar la presencia o exposición a Leptospira y hantavirus. Los órdenes Carnivora (16), Chiroptera (12) y Cetartiodactyla
(12) también han recibido atención de la comunidad científica. Sólo dos estudios incluyeron una especie de lagomorfo y un artículo involucró un miembro del orden Didelphimorphia. Ningún estudio determinó infección viral o bacteriana en miembros de los órdenes Paucituberculata, Microbiotheria y Xenarthra.

Estudios sobre infecciones bacterianas y virales se enfocaron mayormente en Chile sur y central, particularmente, desde las regiones de Coquimbo a Los Lagos. Las regiones más estudiadas fueron la Región de Los Ríos con 24 estudios, la Región Metropolitana con 14 estudios y la Región de Los Lagos con 13 estudios. Sólo tres estudios
Figura 1. Número de estudios científicos relacionados con infecciones virales o bacterianas en distintos ordenes de mamíferos desde 1980 al 2018.
Figura 2. Número de estudios científicos destinados a evaluar la prevalencia de infecciones virales o bacterianas en mamíferos silvestres en Chile desde 1951 a 2018. 
en rabia y un único estudio en hantavirus fueron llevados a cabo en la Región del Maule. Estudios de investigación relacionados con mamíferos de las regiones del norte de Chile son escasos, con dos estudios en la Región de Antofagasta y un estudio en las regiones de Tarapacá y Atacama. No se han realizado estudios en la Región de Arica y Parinacota. Un total de 7 y 4 estudios han sido desarrollados en las regiones de Aysén y Magallanes, respectivamente.

La mayoría de los estudios aplicaron métodos serológicos para el diagnóstico de patógenos en hospedadores mamíferos, como es el caso de los virus distemper y parvovirus y la bacteria Brucella, los que han sido diagnosticados únicamente utilizando serología. Estos métodos también fueron utilizados en estudios de investigación asociados a la determinación de hantavirus en roedores silvestres. La aplicación de métodos moleculares se ha incrementado en las últimas dos décadas en Chile, lo que se ha reflejado en un aumento en el número de estudios que utilizan estas técnicas para el diagnóstico de virus y bacterias en mamíferos silvestres. El uso de otros métodos, como la inmunofluorescencia directa, el cultivo bacteriano y la histopatología han sido mayoritariamente restringidos al diagnóstico de ciertos patógenos.

\section{Discusión}

Los mamíferos silvestres han jugado un rol importante como reservorios de enfermedades infecciosas en estos países y han estado involucrados en la ocurrencia de eventos epizoóticos de “derrame” (spillover en inglés), a poblaciones humanas ${ }^{3}$.

En Chile, gran parte de los investigadores e instituciones gubernamentales han destinado sus esfuerzos a estudiar aquellos agentes zoonóticos considerados una amenaza seria para la salud humana, como la Leptospira $\mathrm{sp}$, el virus de la rabia y el hantavirus. Los patógenos restringidos a hospederos animales y que no representan un riesgo para los humanos (e.g.: virus del distémper canino) sólo han comenzado a recibir atención científica en años recientes, por lo que la información disponible acerca de éstos es mucho más limitada.

\section{Leptospira}

La leptospirosis es una enfermedad zoonótica distribuida a nivel mundial y de gran relevancia para la salud humana, particularmente en países en desarrollo y con bajos ingresos, donde las condiciones sanitarias y los recursos destinados al diagnóstico y prevención de esta enfermedad son limitados ${ }^{15}$. El agente causal de la leptospirosis, Leptospira sp, es un patógeno capaz de infectar a una gran variedad de hospederos mamíferos y sobrevivir en el ambiente por varios meses en zonas predominantes en climas cálidos y húmedos ${ }^{16}$. Los roedores juegan un rol importante en la mantención y diseminación de Leptospira patógena y no patógena a otras especies de mamíferos en zonas urbanas y rurales de Chile, incluyendo humanos y animales domésticos ${ }^{17,18}$. Hasta la fecha, existe evidencia de infección con este patógeno en nueve especies de roedores en el país: el degu (Octodon degus), el ratón oliváceo (Abrothrix olivaceus), el ratón de pelo largo (Abrothrix longipilis), el ratón orejudo (Phyllothis darwini), el ratón colilargo (O. longicaudatus), la rata negra (Rattus rattus), la rata noruega ( $R$. norvergicus), el ratón doméstico (Mus musculus) y el ratón topo valdiviano

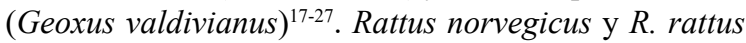
son reservorios particularmente relevantes debido a la alta prevalencia de Leptospira observada en estas especies en zonas rurales del país ${ }^{18,27}$. Esta bacteria ha sido descrita en mamíferos silvestres en la zona centro-sur de Chile, específicamente en las regiones Metropolitana, Los Ríos, Los Lagos y Aysén.

Los registros disponible que indican la presencia de Lepotospira sp en otros órdenes de mamíferos son escasos en comparación a la información existente en roedores, ya que esta bacteria ha sido reportada en sólo dos especies carnívoras: el lobo marino sudamericano (Otaria flavescens) y el visón americano (Neovison vison) $)^{9,28}$. La interacción entre animales silvestres y reservorios domésticos (i.e.: perros y ganado), puede ser un mecanismo importante para la ocurrencia de casos de leptospirosis en ambientes habitados por el hombre ${ }^{29}$.

Futuros estudios dedicados a evaluar el rol de especies silvestres en la mantención y transmisión de Leptospira sp contribuirán de manera importante al entendimiento de las dinámicas de este patógeno en áreas naturales y urbanas del país.

\section{Virus de la rabia}

La rabia es una zoonosis cosmopolita de gran importancia en la salud pública mundial ${ }^{30}$. Todos los mamíferos pueden ser infectados con el virus, pero sólo los quirópteros y carnívoros han sido capaces mantener y transmitir con éxito la infección en el largo plazo ${ }^{30}$. Los casos confirmados de rabia han sido caracterizados por el ISP en diferentes variantes antigénicas, a través de la utilización de anticuerpos monoclonales específicos. Cada variante representa un grupo de virus dentro de un serotipo que posee características antigénicas definidas ${ }^{31}$. Este método de caracterización antigénica de la rabia ha sido utilizado ampliamente en Chile para estudiar su distribución geográfica y temporal en el país ${ }^{32,33}$.

El primer caso de rabia humana en Chile fue reportado en 1879 y la vigilancia en animales domésticos y silvestres ha sido realizada por el ISP (en aquel entonces llamado Instituto Bacteriológico de Chile) desde 1929 $9^{34,35}$. Desde ese momento, la fauna silvestre y los animales 
domésticos han sido reportados como infectados con el virus en todas las regiones del país, entre los que se encuentran animales de ganado, lagomorfos, roedores, carnívoros y quirópteros ${ }^{33,34}$. Sin embargo, la vigilancia activa de la rabia sólo empezó después del primer brote de esta enfermedad en murciélagos, específicamente, en el murciélago cola de ratón (Tadarida brasiliensis) en $1985^{33}$. Después de ese evento, sólo se han reportado casos en murciélagos y no hay evidencia en la literatura sobre su presencia en otras especies silvestres ${ }^{33,36}$. Hasta la fecha, cinco variantes antigénicas se han reportado en Chile, incluyendo la variante antigénica canina AgV2 y cuatro variantes asociadas con murciélagos insectívoros: la variante antigénica AgV4 Tadarida, la variante antigénica AgV6 Lasiurus, la variante antigénica AgV3 Myotis chiloensis y la variante antigénica $\mathrm{AgV}$ no tipificada para Histiotus $^{33,37,38}$. La variante registrada más frecuentemente en Chile desde el 2008 al 2013 ha sido la AgV4 ${ }^{39}$. Las variantes antigénicas son descritas como hospedadorespecíficas entre murciélagos ${ }^{38,40}$, pero estudios recientes sugieren que podría existir una transmisión cruzada de distintos virus de la rabia entre diferentes especies de quirópteros ${ }^{32,38,41,42}$.

Seis de las once especies de murciélago distribuidas en el país han sido descritas con el virus: el murciélago orejudo mayor (Histiotus macrotus), el murciélago orejudo menor (Histiotus montanus), el murciélago oreja de ratón del sur (M. chiloensis), el murciélago colorado (Lasiurus borealis), murciélago gris (Lasiurus cinereus) y el Murciélago cola de ratón (T. brasiliensis) $)^{32,33,37,43}$. Considerando la información científica disponible, $T$. brasiliensis y L. cinereus permanecen como los reservorios de rabia más relevantes en Chile ${ }^{32,36,37,41,43,44}$. Escobar y cols. (2013) indica que ambos $T$. brasiliensis y $L$. cinereus y sus respectivas variantes antigénicas de rabia (AgV4 y AgV6) comparten nichos ecológicos similares en Chile y su distribución está limitada por la presencia de barreras ecológicas naturales, como la Cordillera de los Andes al este y el Océano Pacífico al oeste ${ }^{32}$. La rabia en murciélagos parece seguir un patrón estacional con picos de positividad durante la temporada cálida (octubre-marzo) y una disminución en los meses fríos ${ }^{33,39}$. Esto puede relacionarse con una reducción en la actividad de los murciélagos durante invierno en el hemisferio sur $\mathrm{y}$, por tanto, una menor probabilidad de transmisión de rabia entre murciélagos y de murciélagos a otras especies susceptibles $^{33,39,45}$.

El incremento en el tamaño de la población y densidad de perros, sumado a la presencia de especies de murciélago (principalmente $T$. brasiliensis) en áreas urbanas, han incrementado el riesgo, a lo largo del país, de eventos de transmisión de rabia desde murciélagos a perros ${ }^{46,47}$. Esto es particularmente importante para la zona central de Chile, la cual posee un alto número de variantes antigé- nicas relacionadas con murciélagos y una mayor riqueza de especies quirópteras ${ }^{33}$. Por ejemplo, distintas zonas de concentración de casos positivos de rabia y de riesgo de eventos de transmisión se han asociado con asentamientos urbanos altamente poblados, como las regiones Metropolitana, del Maule, Biobío y Valparaíso ${ }^{33,39,47}$. Se han reportado casos de rabia en carnívoros silvestres en años previos a $1990^{48}$; sin embargo, actualmente se considera a los murciélagos insectívoros como el reservorio más importante de rabia en Chile, representando el $97.31 \%(1339 / 1379)$ de casos positivos reportados por el ISP desde 1985 al $2012^{32}$. La importancia de los murciélagos como reservorios de rabia y el incremento de la población de perros silvestres en Chile, aumentan la preocupación acerca del riesgo actual de transmisión de rabia desde murciélagos a perros y, en consecuencia, a seres humanos ${ }^{47}$.

\section{Hantavirus}

Siete especies de roedores han sido indicadas como expuestas o infectadas con la cepa Andes del virus hanta en Chile: el ratón oliváceo (A. olivaceus), el ratón de pelo largo (A. longipilis), el ratón orejudo ( $P$. darwini), el pericote austral (Loxodontomys micropus), la rata negra ( $R$. rattus), la rata noruega ( $R$. norvergicus) y el ratón colilargo $(O \text {. longicaudatus })^{49-57}$. Estas especies han sido reportadas como infectadas en áreas de Chile central y sur, particularmente desde las regiones de Coquimbo a Magallanes. Hasta la fecha, la presencia de hantavirus en el país se ha restringido únicamente a roedores y no ha sido posible identificar el virus en especies silvestres pertenecientes a otros órdenes como es el caso de marsupiales y quirópteros ${ }^{54}$.

Oligoryzomys longicaudatus es el reservorio más importante de la cepa Andes en Chile, con infecciones en humanos ocurriendo a lo largo del rango de distribución de esta especie desde las regiones de Copiapó a Magallanes $^{54,57-59}$. Oligoryzomys longicaudatus se ha caracterizado por ser una especie altamente móvil, lo que incrementa el riesgo de interactuar con humanos en su amplio rango de hogar (320-4.800 $\left.\mathrm{m}^{2}\right)^{60}$. Esta especie se puede encontrar cercana a áreas urbanas, habitando ambientes húmedos, como bosques y áreas cubiertas de arbustos cercanas a fuentes de agua ${ }^{60}$. El incremento en la densidad de poblaciones de roedores silvestres en áreas peri-urbanas se ha asociado con el aumento en el número de casos de síndrome cardiopulmonar por hantvirus (SCPH) en humanos ${ }^{51}$. Se ha sugerido que la elevación explosiva en el número de roedores durante los años de florecimiento de bambúceas nativas, como la Chusquea quila (letra cursiva), podría esta implicado en la ocurrencia de brotes de hantavirus en humanos debido al incremento en la disponibilidad de alimento por parte de estas plantas ${ }^{51,52}$. La mayor parte de los casos de infección por hantavirus en Chile ocurren 
cerca de pueblos en áreas rurales y peri-urbanas donde $O$. longicaudatus está presente y los pobladores pueden estar más expuestos a infectarse con el virus ${ }^{55,61,62}$.

\section{Mycobactrium}

Mycobacterium avium subp. paratuberculosis (MAP) es un patógeno importante del ganado bovino y pequeños rumiantes y causa pérdidas importantes en producción animal a nivel mundial ${ }^{63}$. En Chile, los ungulados nativos se encuentran en riesgo constante de infectarse con MAP debido a la alta prevalencia de este patógeno reportada en animales de abasto, particularmente en el sur del país $^{64}$. El guanaco (Lama guanicoe), el pudú (Pudu puda) y la liebre europea (Lepus europaeus) han sido reportados como portadores de la bacteria en Chile ${ }^{65-69}$. Los guanacos infectados con MAP no demostraron problemas de salud y la falta de lesiones macroscópicas y microscópicas en la liebre europea indican que estas especies no servirían como reservorios de MAP en la naturaleza, y sólo poseerían la capacidad de transmitir la bacteria mecánicamente ${ }^{65,68}$.

Los cérvidos nativos han sido reportados como prevalentes a la infección con $\mathrm{MAP}^{66,70}$. Por ejemplo, infecciones con MAP son documentadas en el huemul (Hippocamelus bisulcus) en el sur de Chile ${ }^{70}$. En este caso, el aislado obtenido de un huemul poseía características moleculares similares a aislados de MAP reportados comúnmente en el ganado en Chile, lo que sugiere fuertemente que estos animales serían responsables de transmitir la infección a los huemules ${ }^{70}$. La situación es preocupante para esta especie amenazada, particularmente en Chile central, donde la población de huemules está enfrentando problemas de conservación severos y su hábitat es frecuentemente perturbado por la presencia de animales domésticos $^{71}$. De forma similar, tres pudúes que fueron encontradas en áreas frecuentadas por ganado lechero, revelaron infecciones con $\mathrm{MAP}^{67}$. En la actualidad, no existen registros que indiquen hallazgos patológicos en MAP en pudúes de vida libre, sin embargo, esta bacteria ha sido señalada como la causa de muerte de un individuo mantenido en cautiverio ${ }^{66}$.

Infecciones con MAP también han sido documentadas en especies de ciervo introducidas en el sur de Chile, como el ciervo rojo (Cervus elaphus) y el ciervo dama (Dama dama), los cuales pudieron transmitir el patógeno a los animales domésticos o viceversa ${ }^{72,73}$. El jabalí europeo (Sus scrofa) se distribuye actualmente en áreas rurales y protegidas del centro-sur de Chile y es considerado como un portador de MAP en Europa ${ }^{74,75}$. Actualmente, no hay reportes de infección con MAP en esta especie en el país. El rol que los ungulados introducidos juegan en la transmisión de MAP y otros patógenos a animales silvestres y al ganado, es un tópico que aun no ha sido explorado en Chile.

\section{Virus del distémper canino}

El distémper es una enfermedad viral prevalente en perros en todo el mundo y capaz de causar afecciones severas en carnívoros silvestres ${ }^{76}$. Un amplio rango de especies de distintas familias, como Canidae, Felidae, Hyaenidae, Mustelidae, Ursidae, Vivirridae y Procyonidae, han sido reportadas como expuestas o infectadas al virus del distémper canino (VDC), en algunos casos, con importantes declives poblacionales ${ }^{76,77}$. El VDC actualmente posee una condición de endémico en poblaciones rurales y urbanas de Chile, con prevalencias que oscilan entre el 51 al $73 \%{ }^{10,78}$. Los perros han sido indicados como la fuente de brotes infecciosos de VDC en poblaciones de zorro gris (Lycalopex griseus) en Chile central ${ }^{10,79,80,81} \mathrm{y}$ son una potencial amenaza para las poblaciones en peligro de zorro de Darwin (Lycalopex fulvipes) del centro-sur de Chile ${ }^{82}$

Hasta la fecha, no hay estudios que apliquen métodos directos para la detección del virus del distémper en fauna silvestre chilena, sin embargo, estudios serológicos han determinado la exposición al virus en el visón americano (N. vison), el lobo marino sudamericano (O. flavescens), el zorro gris (L. griseus) y el zorro culpeo (Lycalopex culpaeus $)^{8,9,79,80,81}$. No existe información sobre la presencia o exposición a distémper en felinos silvestres y mustélidos autóctonos en el país.

\section{Patógenos y mamíferos silvestres desatendidos}

Esta sección incluye patógenos que han recibido poca atención por parte de la comunidad científica en Chile y la información acerca de su presencia y epidemiología en hospedadores naturales es actualmente insuficiente o inexistente.

Los parvovirus han sido detectados en un amplio rango de carnívoros silvestres alrededor del mundo, pertenecientes a las familias Canidae, Felidae y Mustelidae $^{83}$. En Chile, los parvovirus caninos (PVC) y felinos (PVF) son afecciones reconocidas en perros y gatos, respectivamente ${ }^{84}$. Evaluaciones serológicas de PVC en L. culpaeus, L. griseus y O. flavescens han determinado la exposición a este virus ${ }^{9,10,80}$. En contraste, no existe información respecto a la presencia o exposición frente al PVF en especies silvestres. Tanto PVC como PVF, han causado problemas gastrointestinales in carnívoros de otras partes del mundo, mientras que las consecuencias patológicas de estos virus en especies chilenas son aún desconocidas.

Como los parvovirus, la información acerca de retrovirus en la fauna chilena es escasa. Mora y cols. (2015), documentan que las guiñas en Chiloé se encuentran infectadas con los virus de la leucemia felina (VLFe) y de la inmunodeficiencia felina (VIF) sin signos clínicos aparentes ${ }^{85}$. Las secuencias nucleotídicas obtenidas de ambos virus en guiñas fueron casi idénticas a aquellas presentes 
en gatos domésticos, sugiriendo que estos pueden estar jugando un rol importante en la transmisión de retrovirus a los felinos silvestres. Algunas especies felinas, como la guiña y el puma (Puma concolor), habitan zonas cercanas a asentamientos humanos y, ocasionalmente, depredan aves de traspatio ${ }^{86}$, lo que incrementa el riesgo de interactuar con gatos domésticos infectados con retrovirus. Los retrovirus han sido detectados en el puma y otros felinos de gran tamaño en Norteamérica ${ }^{87}$; sin embargo, la presencia de estos agentes virales en poblaciones de puma y en la mayoría de las especies de felinos en Chile, aún requiere ser investigada.

Información acerca de patógenos virales y bacterianos en rumiantes nativos es muy escasa. El virus de la diarrea viral bovina (VDVB) fue detectado en el pudú $\mathrm{y}$ dos huemules fueron reportados como expuestos al virus $^{88,89}$. Similar al MAP, los aislados obtenidos de VDVB en el pudú, presentan características similares a los virus circulantes en el ganado, lo que fortalece la idea de que los animales de abasto están actuando como diseminadores de patógenos a la fauna silvestre en Chile $^{70,88}$. Otros patógenos presentes en el ganado, como el virus de la rinotraqueitis infecciosa bovina (IBR) y Brucella spp., fueron evaluados en el huemul utilizando métodos serológicos y ningún animal fue determinado como expuesto ${ }^{89}$.

No existe información acerca de infecciones con patógenos virales y bacterianos en carnívoros acuáticos, como los miembros de las familias Otariidae, Phocidae y Mustelidae, con la excepción del lobo marino sudamericano (O. flavescens) y el visón americano $(N$. vison). Además, los cetáceos han sido mayormente ignorados por la comunidad científica local, con sólo un patógeno identificado en Chile ${ }^{90,91}$. El delfín chileno (Cephalorhynchus eutropia), la marsopa negra (Phocoena spinipinnis) y el delfín nariz de botella (Tursiops truncatus) han presentado marcas en sus cuerpos típicas de la enfermedad del tatuaje ("tatto skin disease"), una afección que puede resultar en mortalidad neonatal y en consecuencias negativas para la dinámica poblacional de la especie hospedadora ${ }^{90,91}$. No existen registros de otros patógenos en cetáceos distribuidos en Chile, a pesar de que el morbillivirus cetáceo y Brucella sp. fueron descritos en especies presentes en la sección peruana del Océano Pacífico.

\section{Patógenos transmitidos por garrapatas}

Las garrapatas son ectoparásitos hematófagos de casi todos los vertebrados terrestres y juegan un rol importante como vectores de patógenos ${ }^{95}$. En Chile, patógenos bacterianos y virales transmitidos por vectores han sido desatendidos y la información existente acerca de la presencia de Anaplasma platys ${ }^{96}$, Ehrlichia canis $^{97}$, "Candidatus Rickettsia andeanae" ${ }^{98}$ y Rickettsia felis ${ }^{99}$, se restringe a animales domésticos. Sin embargo, un estudio reciente ha identificado a "Candidatus Neoehrlichia chilensis" en especies de roedores silvestres en el sur de Chile, utilizando técnicas moleculares ${ }^{100}$.

Recientemente, Borrelia burgdorferi fue reportada en Brazil, Mexico, Canada, Chile, Costa Rica, Colombia y Venezuela $^{101}$. Sin embargo, gran parte de los casos han sido diagnosticados basados únicamente en evidencia clínica y serológica, sin una caracterización molecular y aislamiento del agente ${ }^{101}$. Esto sólo ha sido realizado por Ivanova y cols. (2014), quienes reportaron Borrelia chilensis VA1, una nueva especie de espiroqueta del grupo Lyme ${ }^{102}$. Adicionalmente, Verdugo y cols. (2017), encontraron la infección con $B$. chilensis en garrapatas Ixodes stilesi recolectadas de un pudú y sugiere que $I$. stilesi puede estar jugando un rol en la mantención de la espiroqueta ${ }^{103}$. Estudios son necesarios para entender adecuadamente los mecanismos de transmisisón natural de esta bacteria y los riesgos de infección para los animales domésticos y humanos.

\section{Transmisión de patógenos entre fauna silvestre y animales domésticos}

La transmisión de patógenos entre especies silvestres y ganado es bidireccional y afecta tanto a la producción animal, como a la conservación de fauna silvestre a lo largo del mundo ${ }^{104}$. Factores, como la invasión humana en áreas habitadas por fauna silvestre y la expansión e intensificación de los sistemas de producción animal en áreas naturales, pueden incrementar el riesgo de contacto y transmisión de patógenos en la interfase ganado-fauna ${ }^{105}$. La interacción entre el ganado y especies silvestres no sólo ocurre en zonas perturbadas por la actividad antropogénica, sino que también en áreas silvestre protegidas del país ${ }^{71,106}$. Patógenos, tales como MAP, VDVB y Corynebacterium pseudotuberculosis están siendo transmitidos desde animales producción a ungulados silvestres con problemas de conservación ${ }^{70,88,107}$. Por esta razón, es de extrema relevancia el entender las consecuencias que estos agentes infecciosos pueden tener en la salud de las especies afectadas y los mecanismos existentes de transmisión de enfermedades entre el ganado y la fauna silvestre.

Los perros son otra amenaza para la fauna silvestre chilena debido a su comportamiento depredador sobre especies silvestres y por su rol como portadores de patógenos infecciosos ${ }^{108}$. Los perros presentes en áreas naturales han sido relacionados con brotes de enfermedades virales en poblaciones de carnívoros, lo que ha resultado en eventos de mortalidad masiva en el pasado $^{109}$. Las poblaciones de perros han incrementado en tamaño y densidad a lo largo de los años en áreas rurales y urbanas de Chile, lo que puede incrementar la posibilidad de encuentros entre animales silvestres 
y perros domésticos y, por tanto, de transmisión de patógenos ${ }^{10,46,78,79,110}$.

\section{Conclusiones}

Hasta el momento, la mayoría de la publicación se ha relacionado con el estudio de patógenos virales y bacterianos zoonóticos en mamíferos silvestres chilenos. Patógenos no zoonóticos y transmitidos por vectores han sido olvidados por la comunidad científica local, a pesar de la importancia que estos poseen para la conservación de fauna silvestre y la salud pública. Es también preocupante que un gran número de estudios ha sido realizado en el sur y centro de Chile y la zona norte del país ha recibido poca atención científica. Investigación acerca de los patógenos virales y bacterianos en los mamíferos silvestres chilenos es aún muy escasa y estudios son necesarios para entender de forma apropiada el rol que ciertas especies pueden estar jugando como reservorios de infección. La información obtenida en futuros estudios dedicados a evaluar la presencia de infección en mamíferos silvestres establecerá la base para realizar estudios más complejos destinados al entendimiento de la epidemiología y ecología de enfermedades infecciosas zoonóticas y no-zoonóticas en el país.

Agradecimientos. Los autores desean agradecer a Andrés Felipe Peña por su asistencia con el manejo de citas. Agradecemos también el apoyo del Proyecto FONDECYT $n^{\circ} 1170972$.

\section{Resumen}

Este estudio organiza toda la información disponible acerca de los patógenos virales y bacterianos de mamíferos silvestres en Chile. Esto fue realizado con el objetivo de identificar patógenos que han sido bien documentados y reconocer aquellos que no han sido apropiadamente estudiados, determinar el número de artículos que han sido publicados anualmente acerca de este tópico e identificar las regiones en Chile que han concentrado el mayor y menor número de estudios relacionados con patógenos virales y bacterianos. Para lograr esto, se seleccionó para revisión un total de 67 artículos científicos publicados en revistas evaluadas por pares desde 1951 al 2018. Los resultados indican que el número de publicaciones ha incrementado por década y hay años en los cuales no se publicaron artículos. La mayoría de los estudios se relacionan con Leptospira, rabia, hantavirus, Mycobacterium avium paratuberculosis (MAP) y distémper. Rodentia, Carnivora, Chiroptera y Cetartiodactyla fueron los órdenes de mamíferos más estudiados. Información acerca de la presencia/ausencia de patógenos fue encontrada en 44 especies de mamíferos silvestres. La mayor parte de las investigaciones buscaron patógenos en Chile sur y central y los métodos de diagnóstico más empleados para el diagnóstico de patógenos fueron serología y técnicas moleculares. En general, la investigación en mamíferos silvestres ha sido dirigida a la evaluación de enfermedades zoonóticas, mientras que aquellas enfermedades transmitidas por vectores y enfermedades no zoonóticas han sido mayormente ignoradas por la comunidad científica. 


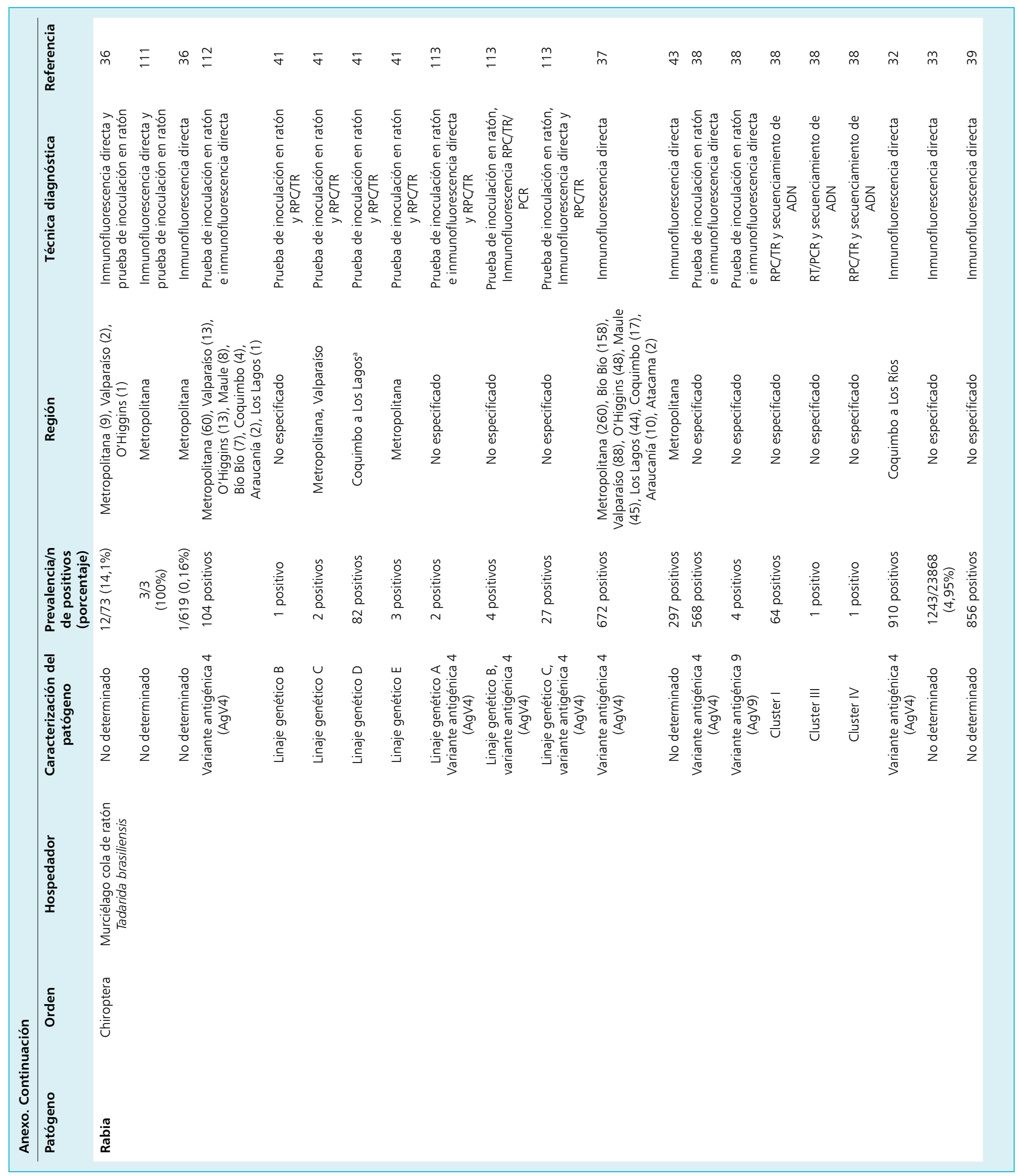




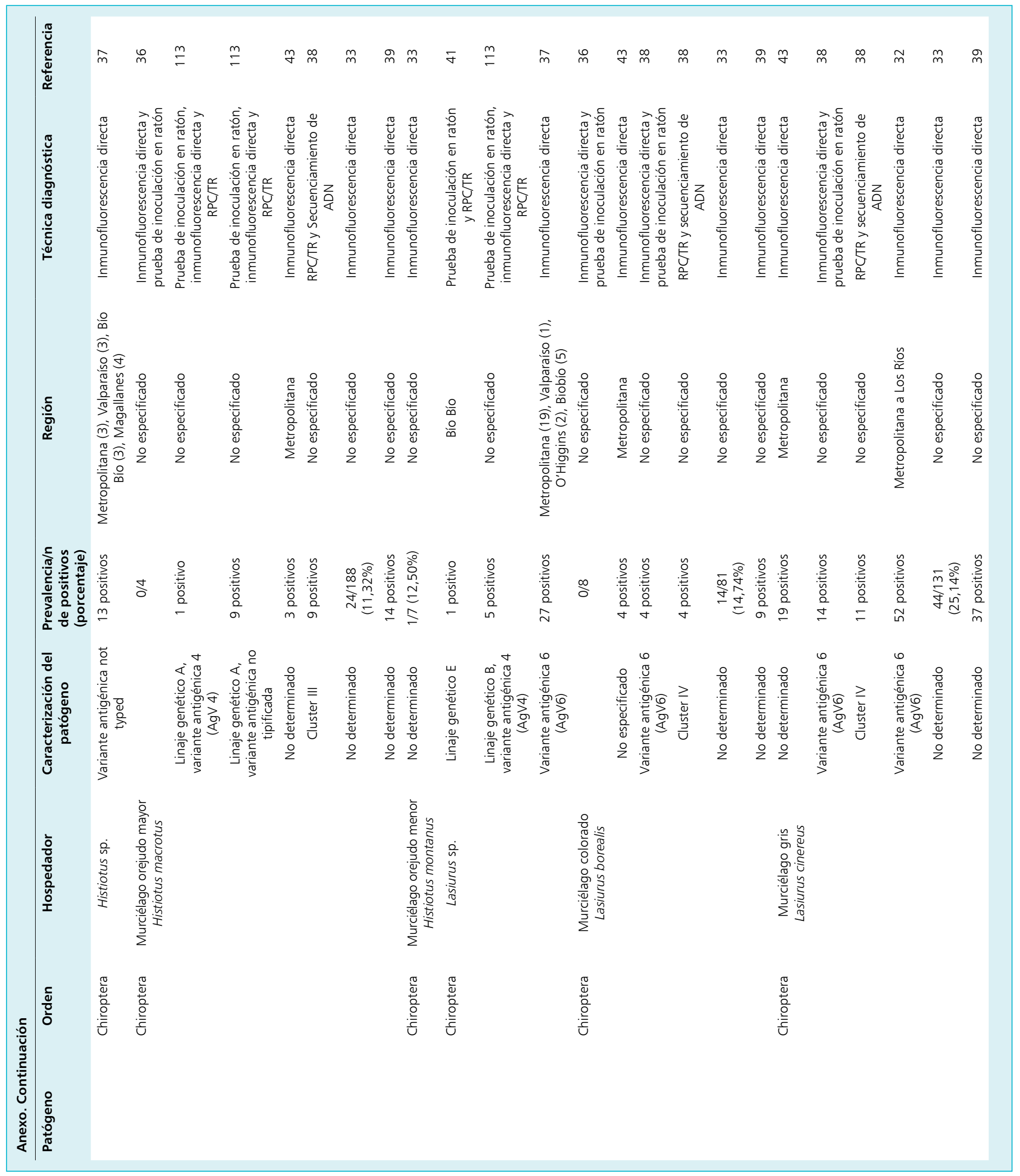




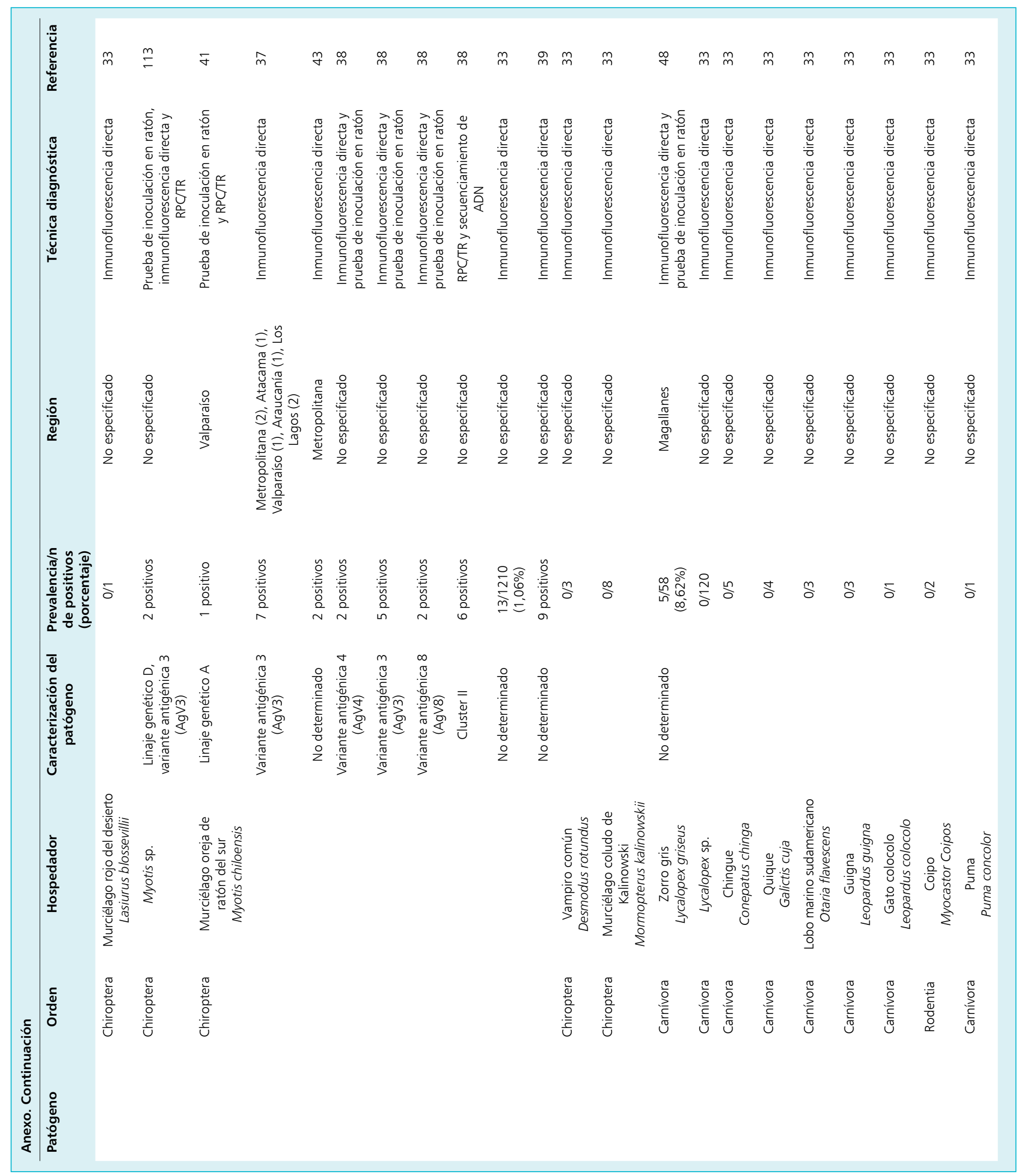




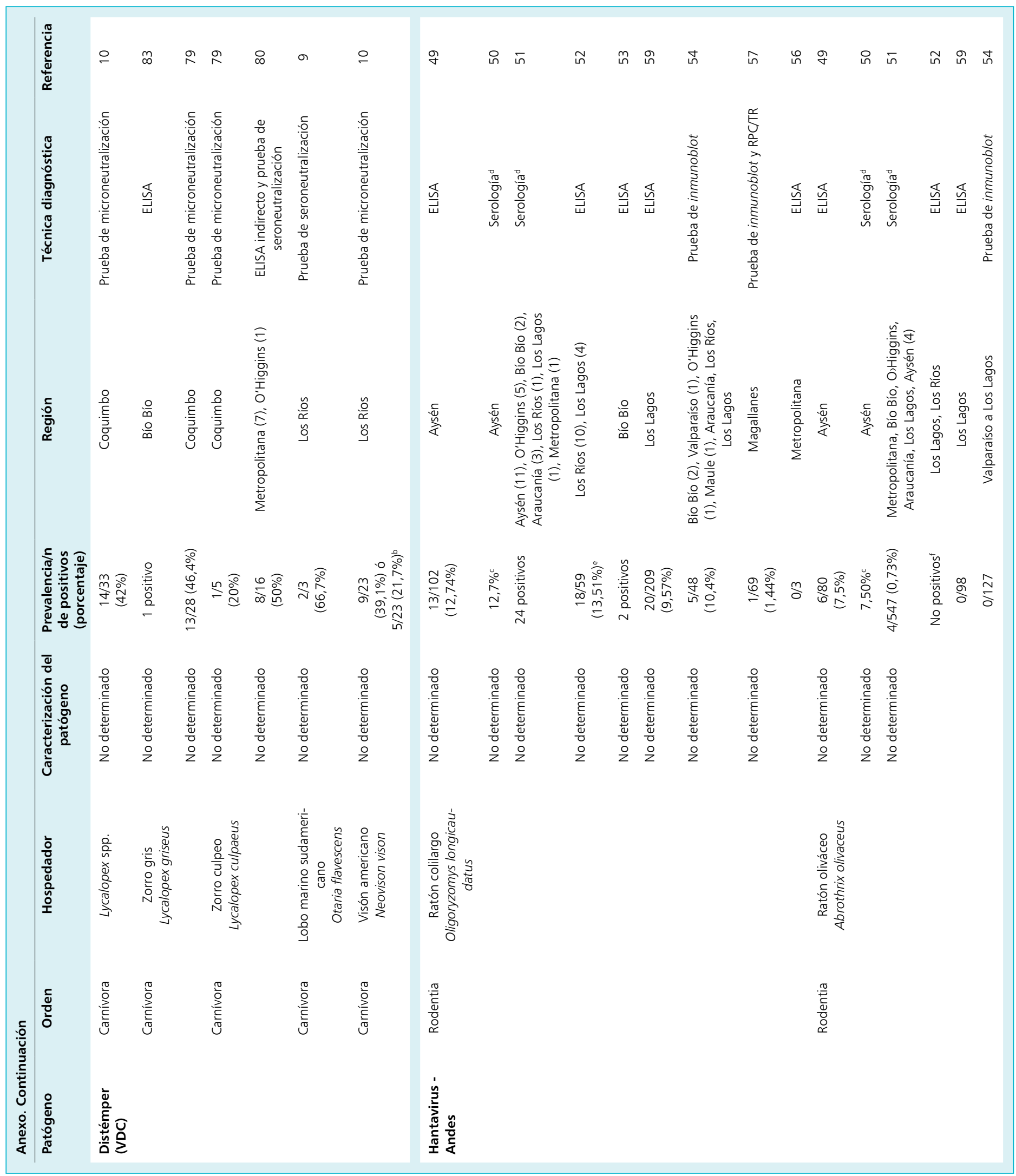




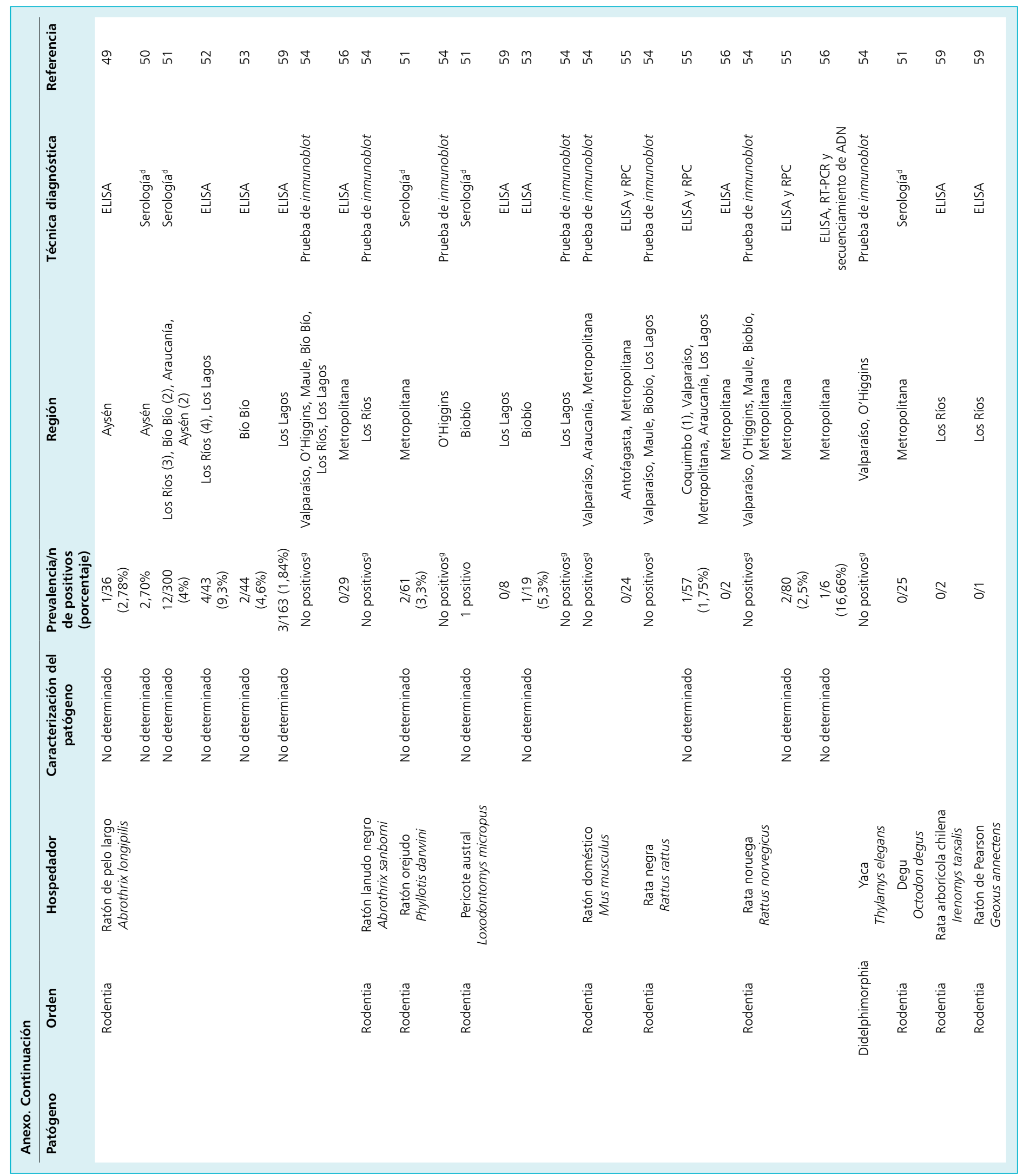




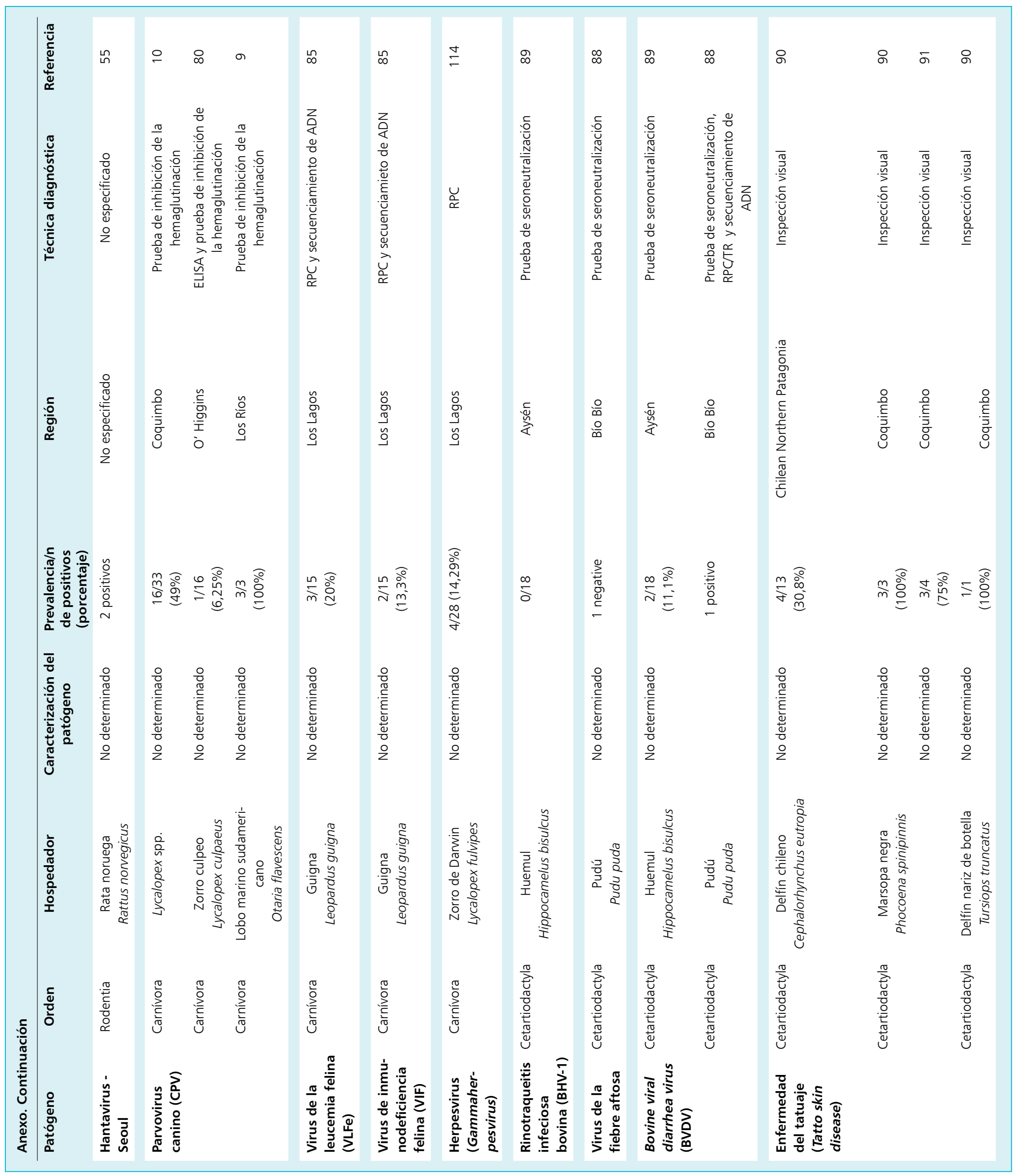




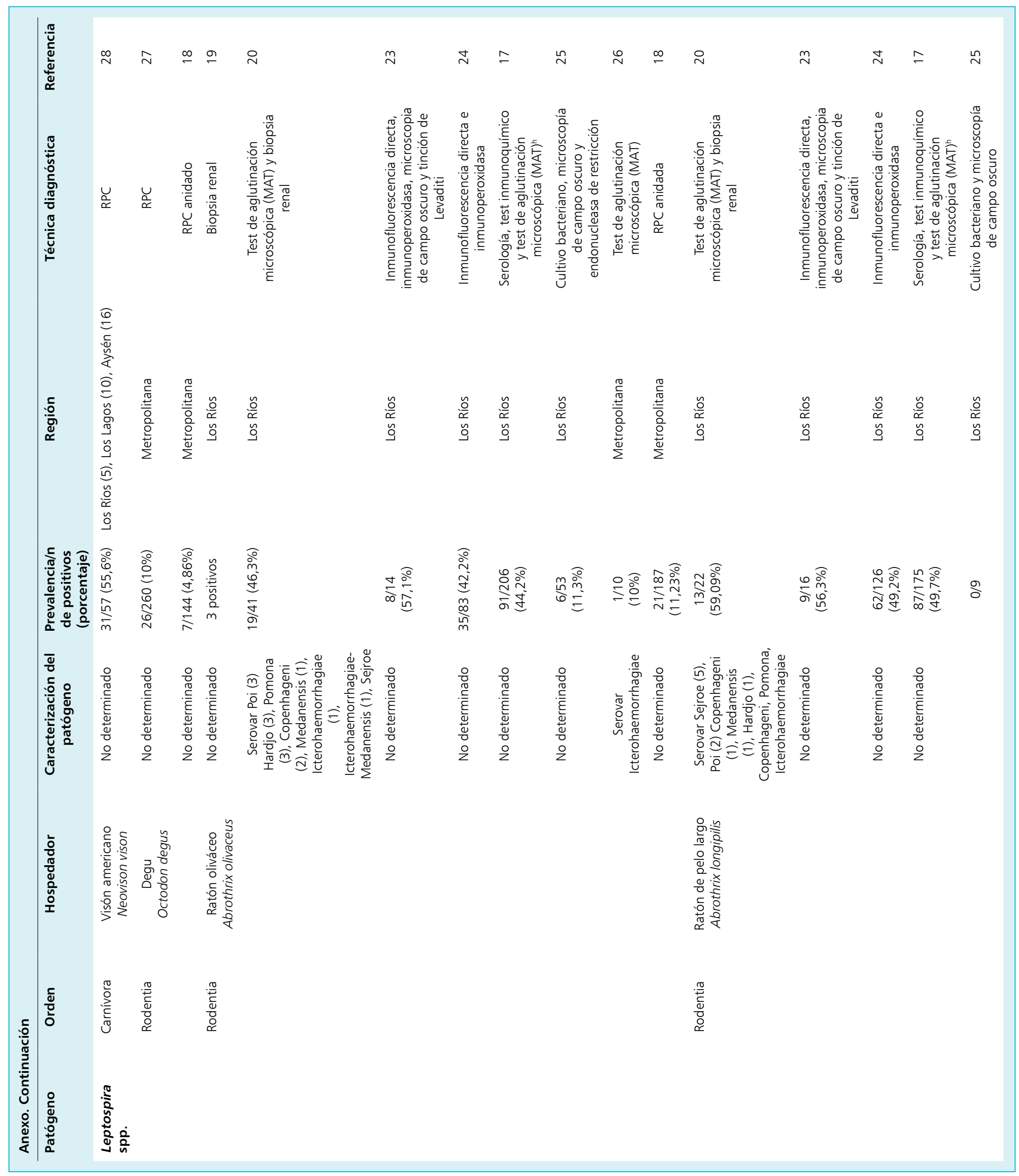




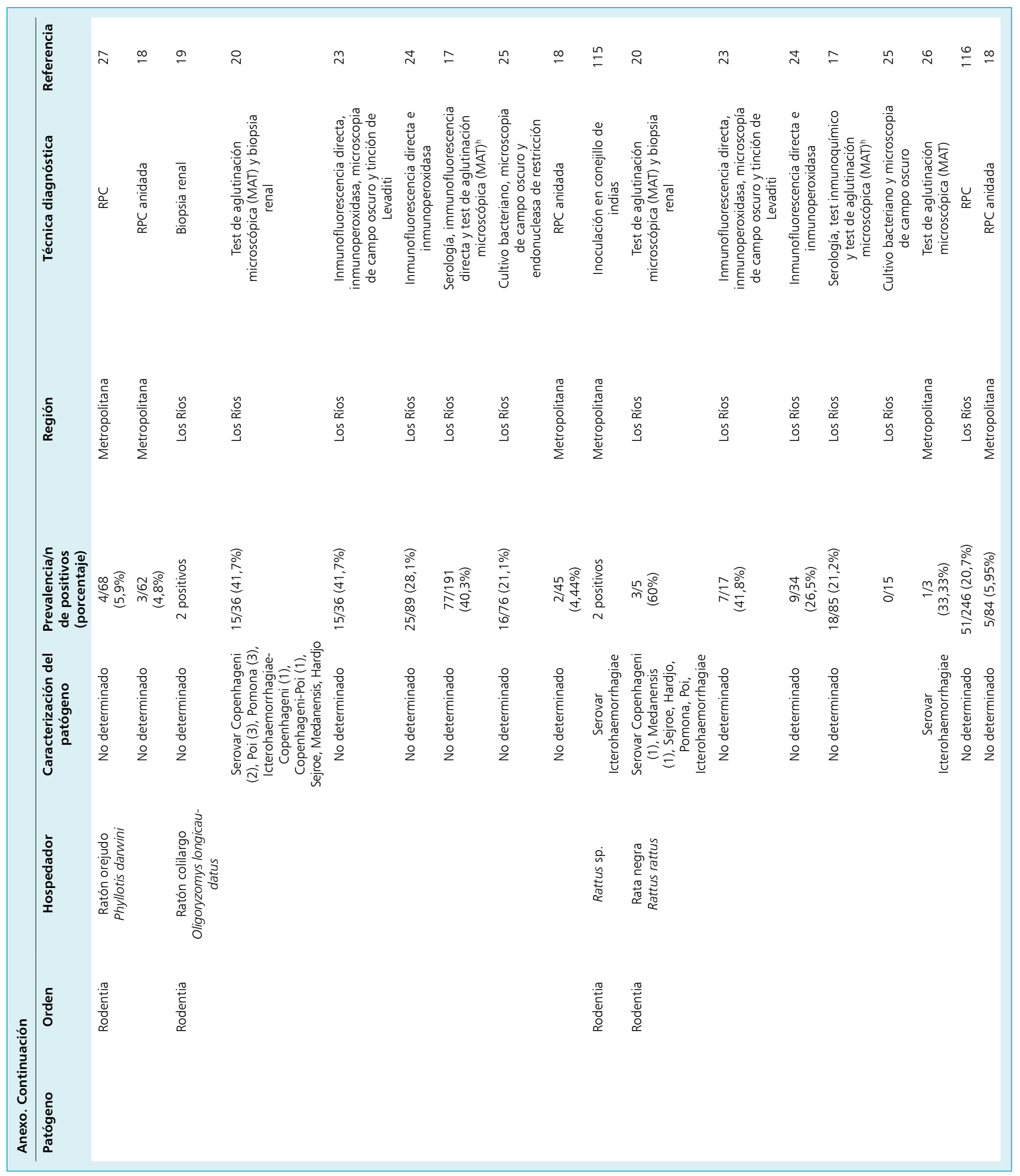




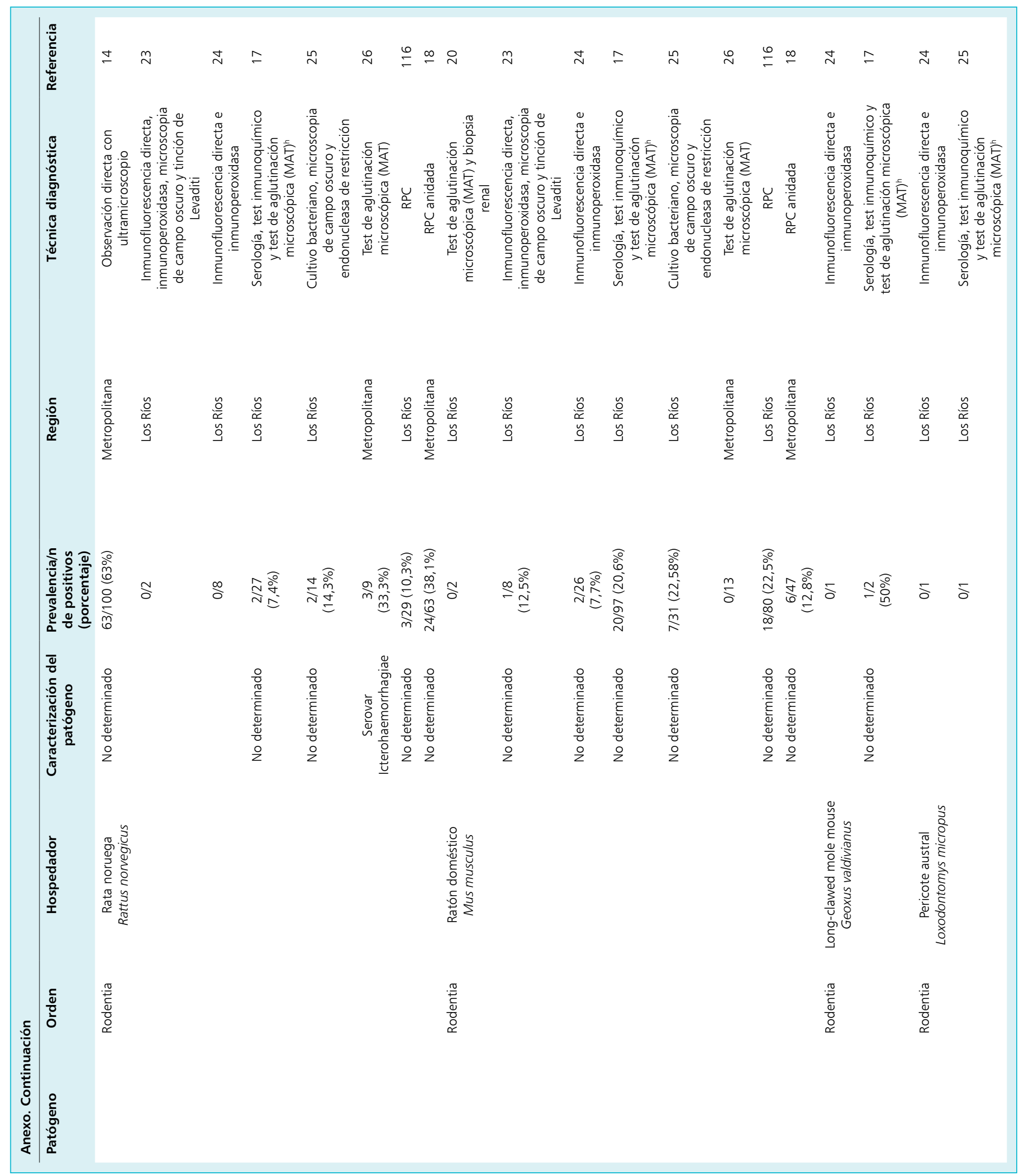




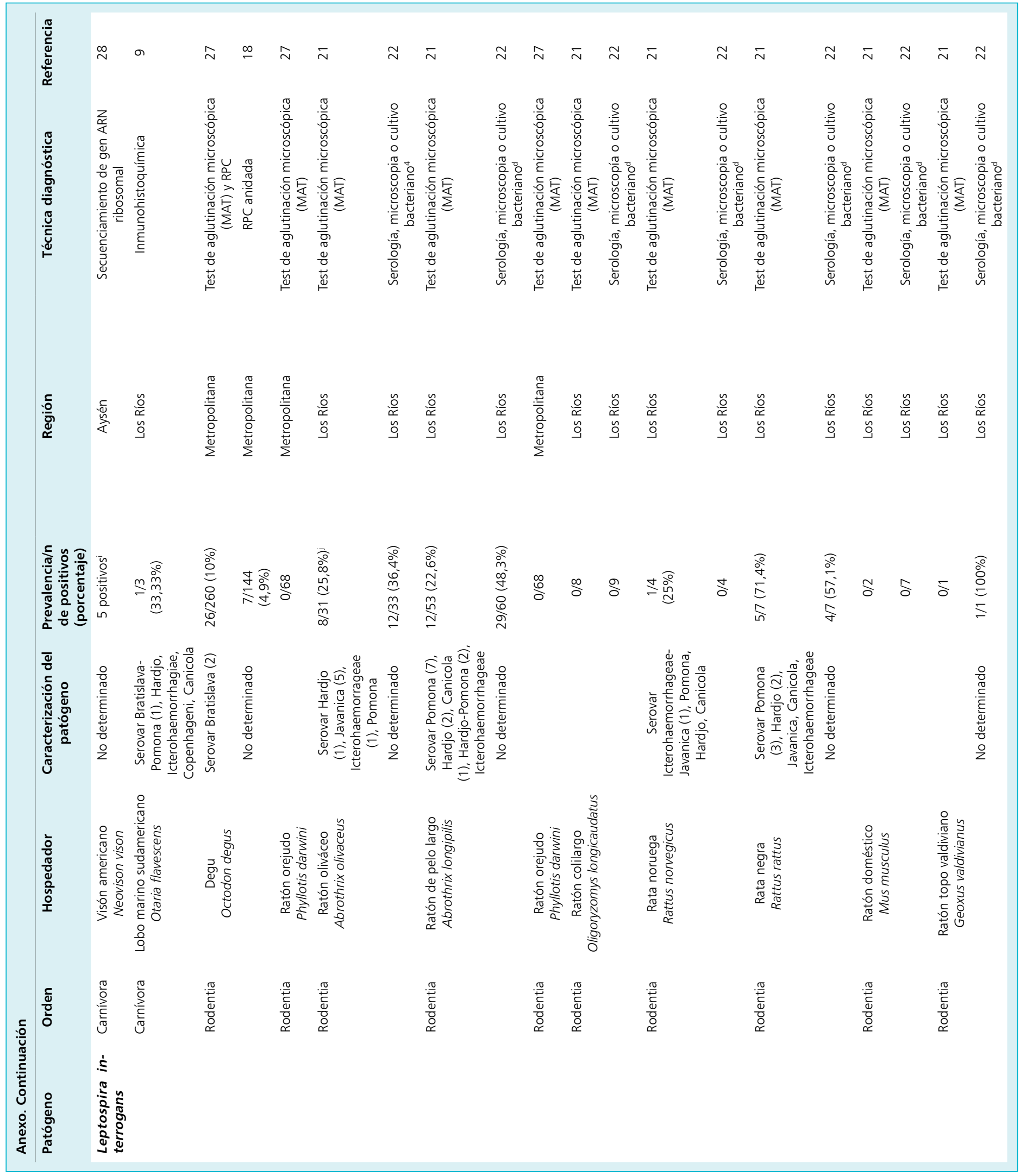




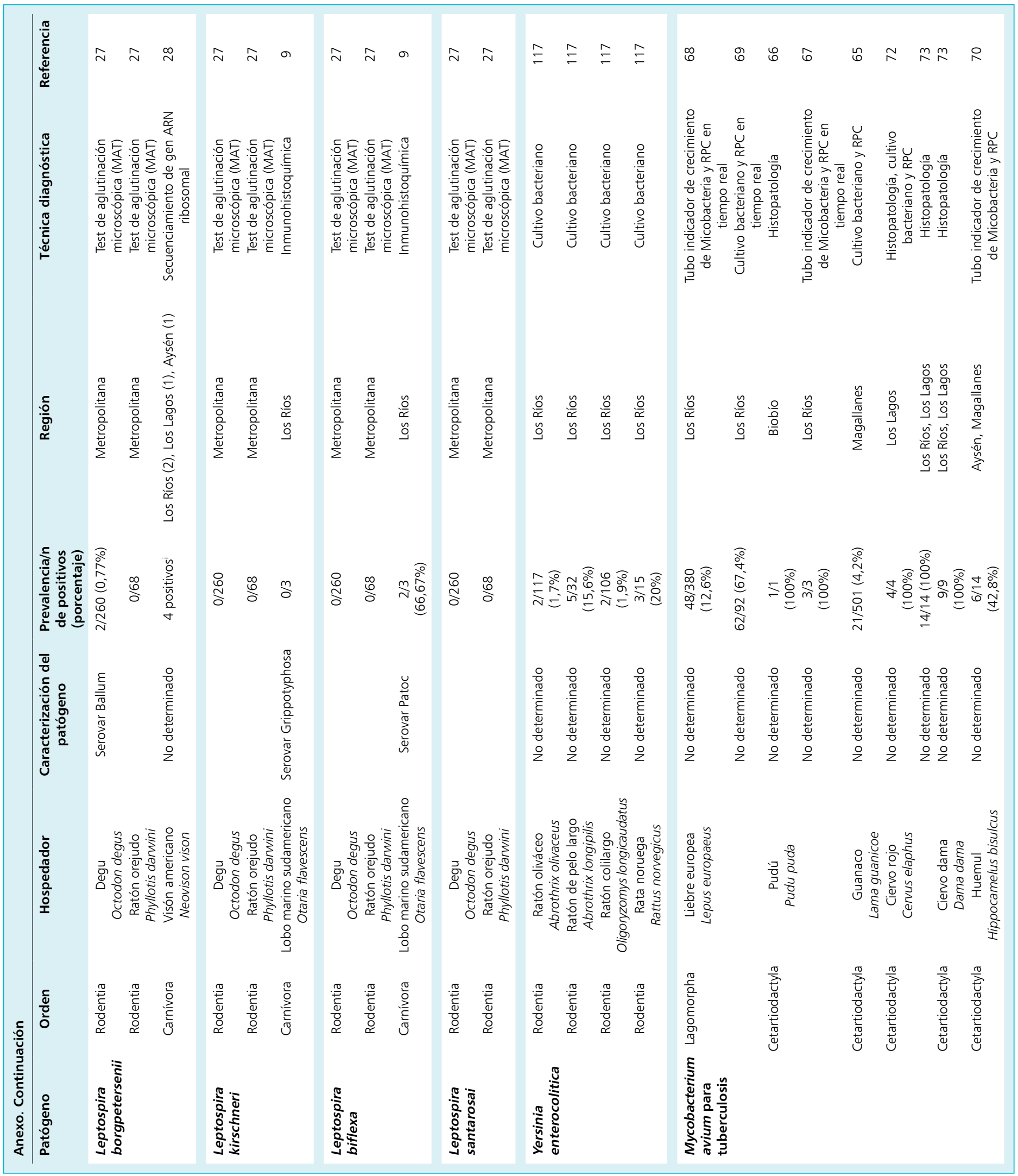




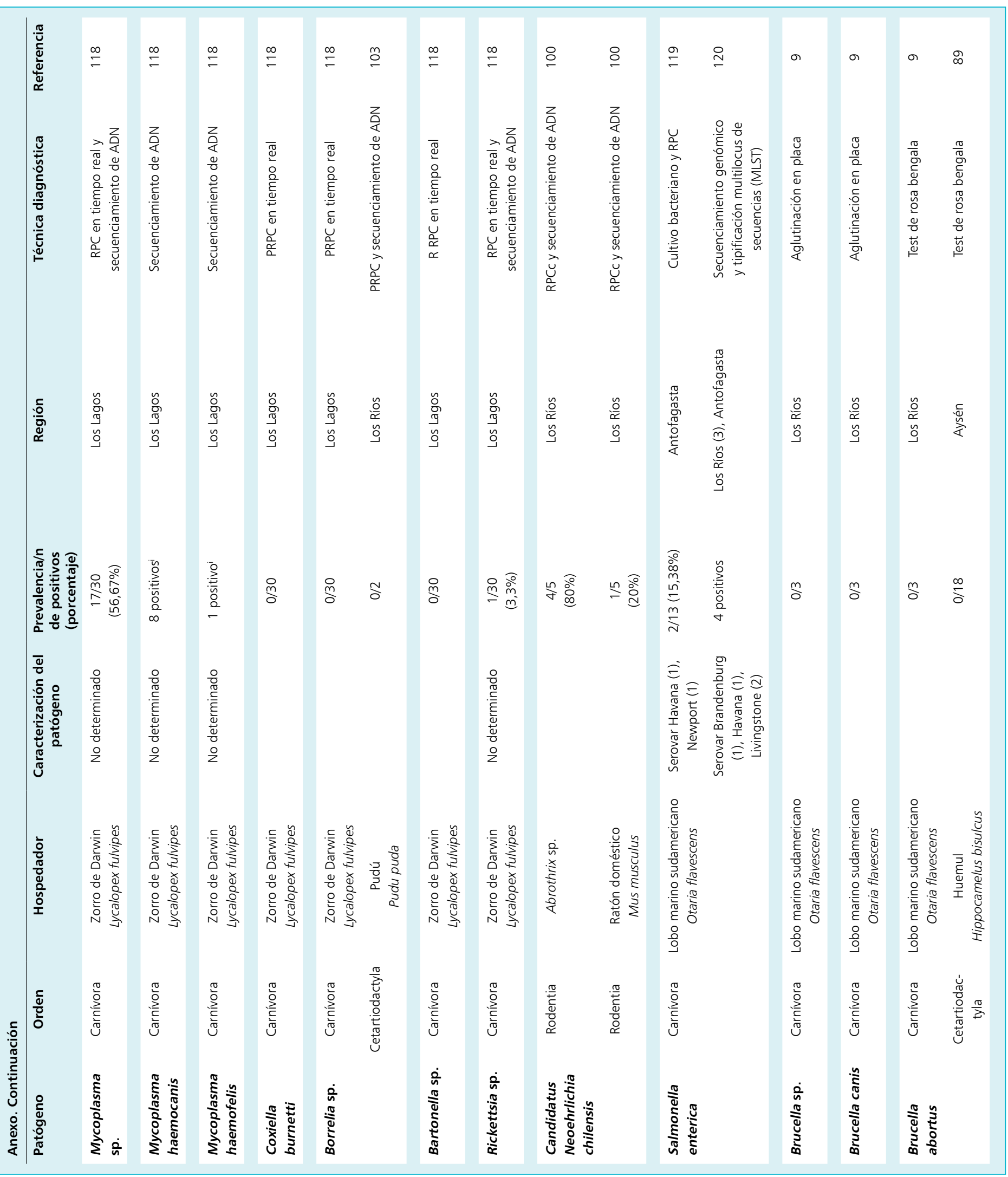




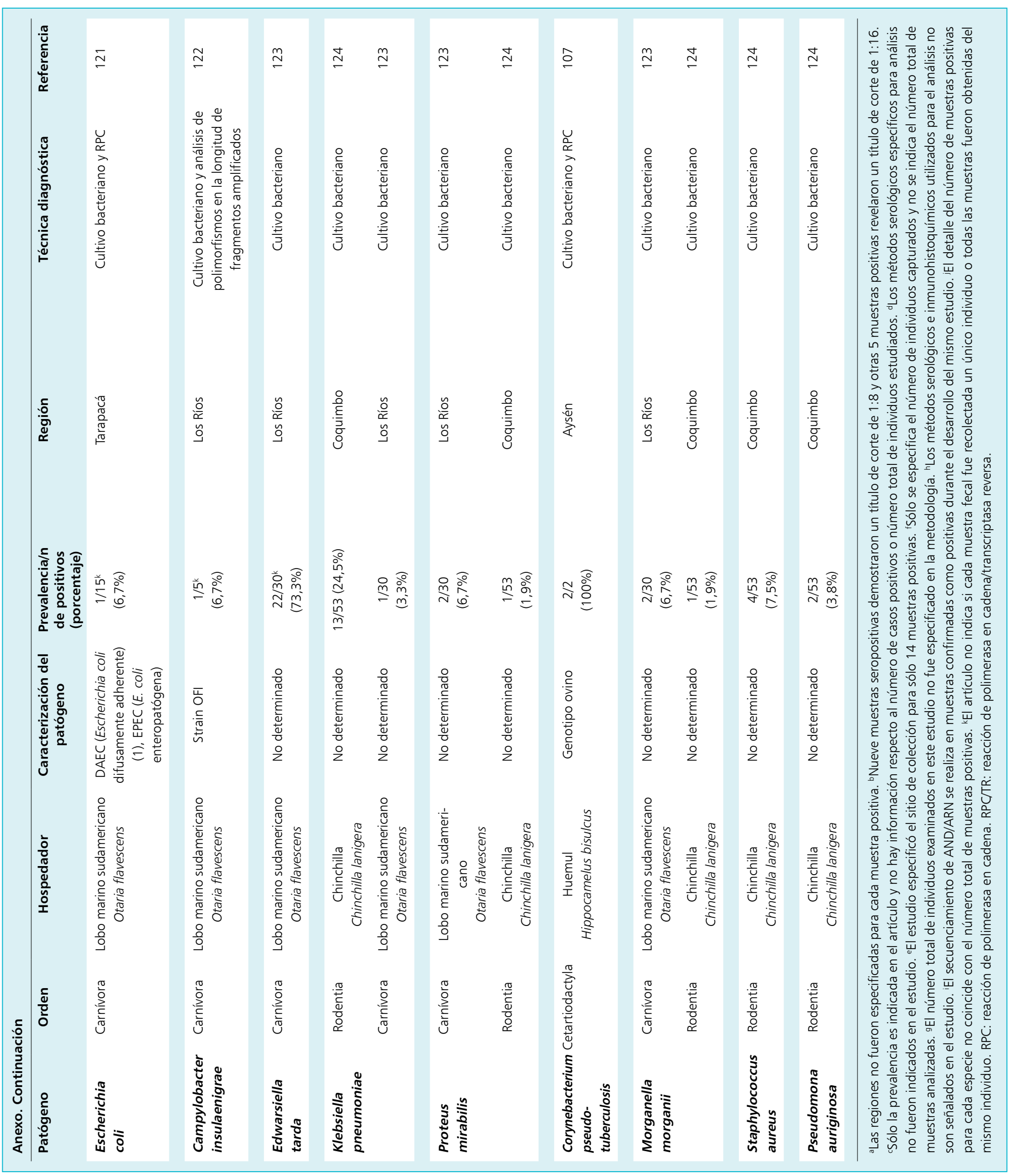




\section{Referencias bibliográficas}

1.- Valenzuela-Sánchez A, Medina-Vogel G Importancia de las enfermedades infecciosas para la conservación de la fauna silvestre amenazada de Chile. Gayana (Concepción) 2014; 78 (1): 57-69. doi: 10.4067/S071765382014000100008.

2.- Daszak P, Cunningham A A, Hyatt A D. Anthropogenic environmental change and the emergence of infectious diseases in wildlife. Acta Trop 2001; 78 (2): 103-16. PMID: 11230820.

3.- Daszak P, Cunningham A A, Hyatt A D. Emerging infectious diseases of wildlife-threats to biodiversity and human health. Science 2000; 287 (5452): 443-9. PMID: 10642539.

4.- Coleman P G, Fèvre E M, Cleaveland S. Estimating the public health impact of rabies. Emerg Infect Dis 2004; 10 (1): 140-2. DOI: $10.3201 /$ eid1001.020774.

5.- Vaheri A, Henttonen H, Voutilainen L, Mustonen J, Sironen T, Vapalahti O. Hantavirus infections in Europe and their impact on public health. Rev Med Virol 2013; 23 (1): 35-49. doi: 10.1002/rmv.1722.

6.- Halliday J E, Allan K J, Ekwem D, Cleaveland S, Kazwala R R, Crump J A. One health: Endemic zoonoses in the tropics: a public health problem hiding in plain sight. Vet Rec 2015; 176 (9): 220-5. doi: 10.1136/vr.h798.

7.- Bradley C A, Altizer S. Urbanization and the ecology of wildlife diseases. Trends Ecol Evol 2007; 22 (2): 95-102. DOI: 10.1016/j. tree.2006.11.001.

8.- Sepúlveda M A, Singer R S, Silva-Rodríguez E A, Eguren A, Stowhas P, Pelican K. Invasive American Mink: Lining pathogen risk between domestic and endangered carnivores. EcoHealth 2014; 11 (3): 409-19. doi: 10.1007/ s10393-014-0917-z.

9.- $\quad$ Sepúlveda M A, Seguel M, Alvarado-Rybak M, Verdugo C, Muñoz-Zanzi C, Tamayo R. Postmortem findings in four south American sea lions (Otaria byronia) from an urban colony in Valdivia, Chile. J Wild Dis 2015; 51 (1): 279-82. doi: 10.7589/2013-07-161.

10.- Acosta-Jamett G, Cunningham A A, Cleaveland S. Serosurvey of canine distemper virus and canine parvovirus in wild canids and domestic dogs at the rural interface in the Coquimbo Region, Chile. Eur J Wildl Res 2015; 61 (2): 329-32. https://doi.org/10.1007/ s10344-014-0886-0.

11.- Medina-Vogel G. Ecología de enfermedades infecciosas emergentes y conservación de especies silvestres. Arch Med Vet 2010; 42 (1): 11-24. https://scielo.conicyt.cl/pdf/amv/v42n1/ art03.pdf.

12.- Moher D, Liberati A, Tetzlaff J, Altman D G. Preferred reporting items for systematic reviews and meta-analyses: the PRISMA statement. Ann Intern Med 2009; 151 (4): 264 9. PMID: 19622511.

13.- Kerry K R, Riddle M. Health of Antarctic wildlife: a challenge for science and policy. Springer Science \& Business Media. 2009. New York.

14.- Neghme A, Jarpa A, Agosin M, Christen $\mathrm{R}$. Indice de infestación por leptospiras en las ratas (Rattus norvegicus) del matadero municipal de Santiago, Chile. Bol Inf Parasitol Chil 1951; 6: 6-7.

15.- Abela-Ridder B, Sikkema R, Hartskeerl R A. Estimating the burden of human leptospirosis. Int J Antimicrob Agents 2010; 36: S5-S7. DOI: 10.1016/j.ijantimicag.2010.06.012.

16.- Levett P N. Leptospirosis. Clin Micrbiol Rev 2001; 14 (2): 296-326. DOI: 10.1128/ CMR.14.2.296-326.2001.

17.- Zamora J, Riedemann S. Animales silvestres como reservorios de leptospirosis en Chile: Una revisión de los estudios efectuados en el país. Arch Med Vet 1999a; 31 (2): 151-6. http://dx.doi.org/10.4067/S0301732X1999000200001.

18.- Correa J P, Bucarey S A, Cattan P E, LandaetaAqueveque C, Ramírez-Estrada J. Renal carriage of Leptospira species in rodents from Mediterranean Chile: The Norway rat (Rattus norvegicus) as a relevant host in agricultural lands. Acta Trop 2017a; 176: 105 8. doi: 10.1016/j.actatropica.2017.07.032.

19.- Zamora J, Murúa R. Infecciones por Leptospira en roedores silvestres. Comunicación preliminar. Arch Med Vet 1976; 8: 424-6.

20.- Riedemann S, Zamora J. Leptospirosis en pequeños roedores en el área rural de Valdivia. Zoonoses Public Health 1982; 29 (10): 764-8. https://doi.org/10.1111/j.1439-0450.1982. tb01195.x.

21.- Riedemann S, Cabezas X, Zamora J. Detección de aglutininas antileptospira en roedores silvestres del área rural de Valdivia, Avances en Ciencias Veterinarias 1994; 9 (1): 162-4 DOI: 10.5354/0719-5273.2010.6139.

22.- Zamora J, Riedemann S, Cabezas X. Relación entre algunos aspectos ambientales y la infección por L. Interrogans en roedores de la provincia de Valdivia. Medio Ambiente 1994; 12: 3-8.

23.- Zamora J, Riedemann S, Cabezas X, Vega S. Comparación de cuatro técnicas microscópicas para el diagnóstico de leptospirosis en roedores silvestres en el área rural de Valdivia, Chile. Rev Lat Microbiol 1995a; 37: 267-2. PMID 8850345 .

24.- Zamora J, Riedemann S, Cabezas X, Lovera P. Leptospirosis de roedores silvestres en el área rural de Valdivia. Pesquisa de Leptospira interrogans mediante inmunofluorescencia e inmunoperoxidasa. Arch Med Vet 1995b; 27 (1): 115-8.

25.- Zamora J, Riedemann S. Aislamiento y sobrevivencia de leptospiras en tejido renal de roedores silvestres. Arch Med Vet 1999b; 31: 103-7. http://dx.doi.org/10.4067/S0301732X1999000100011.

26.- Perret C, Abarca K, Dabanch J, Solari V, García P, Carrasco S, et al. Prevalencia y presencia de factores de riesgo de leptospirosis en una población de riesgo de la Región Metropolitana. Rev Med Chile 2005; 133 (4): 426-31. DOI: /S0034-98872005000400005

27.- Correa J P, Bacigalupo A, Botto-Mahan C, Bucarey S, Cattan P E, García de Cortazar R, et al. Natural infection of Leptospira species in the native rodents Degu (Octodon degus) and Darwin's Pericote (Phyllotis darwini) in mediterranean Chile. J Wild Dis 2017b; 53: 677-80. doi: 10.7589/2016-11-248.

28.- Barros M, Sáenz L, Lapierre L, Núñez C, Medina-Vogel G. High prevalence of pathogenic Leptospira in alien American mink (Neovison vison) in Patagonia. Rev Chil Hist Nat 2014; 87(1): 19. http://dx.doi.org/10.1186/ S40693-014-0019-X.

29.- Lelu M, Muñoz-Zanzi C, Higgins B, Galloway R. Seroepidemiology of leptospirosis in dogs from rural and slum communities of Los Rios Region, Chile. BMC Vet Res 2015; 11 (1): 31. doi: 10.1186/s12917-015-0341-9.

30.- Hankins D G, Rosekrans J A. Overview, prevention, and treatment of rabies. Mayo Clin Proc 2004; 79 (5): 671-6. DOI: 10.1016/ S0025-6196(11)62291-X

31.- Rupprecht C E, Hanlon C A, Hemachudha T. Rabies re-examined. Lancet Infect Dis 2002; 2 (6): 327-43. PMID: 12144896.

32.- Escobar L E, Peterson A T, Favi M, Yung V, Pons P J, Medina-Vogel G. Ecology and geography of transmission of two bat-borne rabies lineages in Chile. PLoS Negl Trop Dis 2013; 7 (12): e2577. DOI: 10.1371/journal. pntd.0002577.

33.- Escobar L E, Restif O, Yung V, Favi M, Pons D J, Medina-Vogel G. Spatial and temporal trends of bat-borne rabies in Chile. Epidemiol Infect 2015; 143 (7): 1486-94. doi: 10.1017/ S095026881400226X. Epub 2014 Aug 28.

34.- Favi M, Durán J C. Epidemiología de la rabia en Chile (1929-1988) y perspectivas en mamíferos silvestres. Avances en Ciencias Veterinarias 1991; 6 (1): 13-21. doi: 10.5354/0719-5273.2010.4623.

35.- Laval E, Lepe P. Una visión histórica de la rabia en Chile. Rev Chilena Infectol 2008; 25 (2): S2-S7. doi: 10.4067/S071610182008000200014.

36.- Favi M, Catalán R. Rabies in bats in Chile. Avances en Ciencias Veterinarias 1986, 1: 73 6. doi: 10.5354/0719-5273.2010.4439.

37.- Favi M, Rodríguez L, Espinosa C, Yung V. Rabia en Chile: 1989-2005. Rev Chilena Infectol 2008; 25 (2): s8-s13. doi: 10.4067/ S0716-10182008000200015. 
38.- Yung V, Favi M, Fernández J. Typing of the rabies virus in Chile, 2002-2008. Epidemiol Infect 2012; 140 (12): 2157-62. doi: 10.1017/ S0950268812000520.

39.- Alegría-Morán R, Miranda D, Barnard M, Parra A, Lapierre L. Characterization of the epidemiology of bat-borne rabies in Chile between 2003 and 2013. Prev Vet Med 2017: 143; 30-8. doi: 10.1016/j. prevetmed.2017.05.012.

40.- Piñero C, Dohmen F G, Beltrán F, Martínez L, Novaro L, Russo S, et al. High diversity of rabies viruses associated with insectivorous bats in Argentina: presence of several independent enzootics. PLoS Negl Trop Dis 2012; 6 (5): e1635. doi: 10.1371/journal. pntd.0001635.

41.- de Mattos C A, Favi M, Yung V, Pavletic C, de Mattos C C. Bat rabies in urban centers in Chile. J Wild Dis 2000; 36 (2): 231-40. DOI: 10.7589/0090-355836.2.2310.

42.- Cisterna D, Bonaventura R, Caillou S, Pozo O, Andreau M L, Dalla Fontana L, et al. Antigenic and molecular characterization of rabies virus in Argentina. Virus Res 2005; 109 (2): 139-47. DOI: 10.1016/j. virusres.2004.10.013.

43.- Favi M C, Bassaletti A C, López J D, Rodríguez L A, Yung V. Descripción epidemiológica del reservorio de rabia en murciélagos de la Región Metropolitana. Chile. 2000-2009. Rev Chilena Infectol 2011; 28 (3): 223-8. doi: 10.4067/s071610182011000300004.

44.- Díaz A M, Papo S, Rodríguez A, Smith J S. Antigenic analysis of rabies-virus isolates from Latin America and the Caribbean. Zentralbl Veterinarmed B. 1994; 41 (3): 153-6.

45.- Bozinovic F, Contreras L C, Rosenmann M, Torres-Mura J C. Bioenergética de Myotis chiloensis (Quiroptera: Vespertilionidae). Rev Chil Hist Nat 1985; 58: 39-45. http://rchn.biologiachile.cl/pdfs/1985/1/ Bozinovic_et_al_1985.pdf.

46.- Acosta-Jamett G, Cleaveland S, Cunningham AA. Demography of domestic dogs in rural and urban areas of the Coquimbo region of Chile and implications for disease transmission. Prev Vet Med 2010; 94 (3): 272-81. doi: 10.1016/j. prevetmed.2010.01.002.

47.- Astorga F, Escobar L E, Poo-Muñoz D A, Medina-Vogel G. Dog ownership, abundance and potential for bat-borne rabies spillover in Chile. Prev Vet Med 2015; 118 (4): 397-405. doi: 10.1016/j.prevetmed.2015.01.002.

48.- Durán J C, Favi M. Rabia en zorro gris (Pseudalopex griseus) patagónico. Magallanes. Chile. Avances en Ciencias Veterinarias 1989; 4: 146-52. doi: 10.5354/0719-5273.2010.4548.

49.- Toro J, Vega J D, Khan A S, Mills J N, Padula P, Terry W, et al. An outbreak of hantavirus pulmonary syndrome, Chile, 1997. Emerg Infect Dis 1998; 4 (4): 687-94. doi: 10.3201/ eid0404.980425.

50.- Baró M, Vergara J, Navarrete M. Hantavirus en Chile: revisión y análisis de casos desde 1975. Rev Med Chile 1999; 127 (12): 1513-23. doi: 10.4067/S0034- 98871999001200015.

51.- Pavletic C. Hantavirus: Su distribución geográfica entre los roedores silvestres de Chile. Rev Chilena Infectol 2000; 17(3): 18696. doi: 10.4067/S0716- 10182000000300002.

52.- Murúa R, Navarrete M, Cádiz R, Figueroa R, Padula P, Zaror L, et al. Síndrome pulmonar por Hantavirus: situación de los roedores reservorios y la población humana en la Décima Región, Chile. Rev Med Chile 2003; 131 (2): 169-76. doi: 10.4067/ S003498872003000200006 .

53.- Ortiz J C, Venegas W, Sandoval J A, Chandía P, Torres F. Hantavirus en roedores de la Octava Región de Chile. Rev Chil Hist Nat 2004; 77 (2): 251-6. doi: 10.4067/S0716078X2004000200005.

54.- Torres-Pérez F, Navarrete-Droguett J, Aldunate R, Yates T L, Mertz G J, Vial P A, et al. Peridomestic small mammals associated with confirmed cases of human hantavirus disease in southcentral Chile. Am J Trop Med Hyg 2004; 70 (3): 305-9. PMID: 15031522.

55.- Lobos G, Ferres M, Palma R E. Presencia de los géneros invasores Mus y Rattus en áreas naturales de Chile: un riesgo ambiental y epidemiológico. Rev Chil Hist Nat 2005; 78 (1): 113-24. doi: 10.4067/ S0716078X2005000100008.

56.- Fernández J, Villagra E, Yung V, Tognarelli J, Araya P, Mora J, et al. Identificación de Hantavirus Andes en Rattus norvegicus. Arch Med Vet 2008; 40 (3): 295-8. doi: $10.4067 /$ S0301-732X2008000300011.

57.- Belmar-Lucero S, Godoy P, Ferres M, Vial P, Palma R E. Range expansion of Oligoryzomys longicaudatus (Rodentia, Sigmodontinae) in Patagonian Chile, and first record of Hantavirus in the region. Rev Chil Hist Nat 2009; 82 (2): 265-75. doi: 10.4067/ S0716078X2009000200008

58.- Gallardo M, Palma R, Systematics of Oryzomys longicaudatus (Rodentia, Muridae) in Chile. J Mammal 1990; 71: 333-42. doi: $10.2307 / 1381943$.

59.- Padula P, Figueroa R, Navarrete M, Pizarro E, Cadiz R, Jofre C, et al. Transmission study of Andes Hantavirus infection in wild Sigmodontine rodents. J Virol 2004; 78 (21): 11972-9. doi: 10.1128/JVI.78.21.1197211979.2004

60.- Murúa R, González LA, Meserve P L. Population ecology of Oryzomys longicaudatus philippii (Rodentia: Cricetidae) in southern Chile. J Anim Ecol 1986; 55 (1): 281-93. doi: $10.2307 / 4708$.
61.- Morales JV. Diagnóstico y manejo del síndrome cardiopulmonar por hantavirus. Chile-2007. Rev Chil Infect 2009; 26 (1): 6886. doi: 10.4067/S0716- 10182009000100013.

62.- Mackelprang R, Dearing D, Jeor S High prevalence of Sin Nombre virus in rodent populations, central Utah: A consequence of human disturbance? Emerg Infect Dis 2001; 7: 480-1. doi: 10.3201/ eid0703.010328.

63.- Kennedy DJ, Benedictus G. Control of Mycobacterium avium subsp. paratuberculosis infection in agricultural species. Rev Sci Tech 2001; 20 (1): 151-79. PMID: 11288510.

64.- Kruze J, Monti G, Schulze F, Mella A, Leiva S. Herd-level prevalence of Map infection in dairy herds of southern Chile determined by culture of environmental fecal samples and bulk-tank milk qPCR. Prev Vet Med 2013; 111 (3): 319-24. doi: 10.1016/j. prevetmed.2013.05.011

65.- Salgado M, Herthnek D, Bölske G, Leiva S, Kruze J. 2009. First isolation of Mycobacterium avium subsp. paratuberculosis from wild guanacos (Lama guanicoe) on Tierra del Fuego Island. J Wild Dis 2009; 45 (2): 295 301. doi: 10.7589/0090-3558-45.2.295

66.- González-Acuña D, Neira-Ramírez V, Moreno-Salas L, Quezada M. First report of paratuberculose in Southern Pudu deer (Artyodactila: Cervidae). Arq Bras Med Vet Zootec 2011; 63 (4): 1025-7. doi: 10.1590/ S0102-09352011000400033.

67.- Salgado M, Aleuy O A, Sevilla I A, Troncoso E. Detection of Mycobacterium avium subsp. paratuberculosis in a cattle/pudu interface. Arq Bras Med Vet Zootec 2015; 67 (5): 1205-9. doi: 10.1590/1678-4162-7530.

68.- Salgado M, Manning E J, Monti G, Bólske G, Soderlund R, Ruiz M. European hares in Chile: a different lagomorph reservoir for Mycobacterium avium subsp. paratuberculosis? J Wild Dis 2011; 47 (3): 734-8. doi: 10.7589/0090-3558-47.3.734.

69.- Salgado M, Monti G, Sevilla I, Manning E. Association between cattle herd Mycobacterium avium subsp. paratuberculosis (MAP) infection and infection of a hare population. Trop Anim Health Prod 2014; 46 (7): 1313-6. DOI: $10.1007 / \mathrm{s} 11250-014-0637-\mathrm{y}$.

70.- Salgado M, Corti P, Verdugo C, Tomckowiack C, Moreira R, Durán K et al. Evidence of Mycobacterium avium subsp. paratuberculosis (MAP) infection in huemul deer (Hippocamelus bisulcus) in Patagonian fjords. Austral J Vet Sci 2017; 49 (2): 135-7. doi: 10.4067/S0719-81322017000200135.

71.- Povilitis A. El estado actual del huemul (Hippocamelus bisulcus) en Chile central. Gayana (Concep) 2002; 66 (1): 59-68. doi: 10.4067/S0717- 65382002000100008. 
72.- Pradenas M, Navarrete-Talloni M J, Salgado M, Zamorano P, Paredes E. Paratuberculosis o tuberculosis aviar en ciervo rojo con diarrea crónica?. Arch Med Vet 2014; 46 (1): 45-52. doi: 10.4067/S0301-732X2014000100007.

73.- Lobão-Tello E R, Herbach E P, NavarreteTalloni MJ. Paratuberculosis: new histopathological findings in red deer (Cervus elaphus) and fallow deer (Dama dama) in Chile. Pesqui Vet Bras 2017; 37 (7): 749-53. doi: 10.1590/S0100736X2017000700016.

74.- Naranjo V, Gortazar C, Vicente J, de la Fuente J. Evidence of the role of European wild boar as a reservoir of Mycobacterium tuberculosis complex. Vet Microbiol 2008; 127 (1-2): 1-9. doi: 10.1016/j.vetmic.2007.10.002.

75.- Skewes O, Jaksic F M. History of the introduction and present distribution of the european wild boar (Sus scrofa) in Chile. Mastozool Neotrop 2015; 22 (1): 113-24. http://www.scielo.org.ar/pdf/mznt/v22n1/ v22n1a12.pdf.

76.- Deem S L, Spelman L H, Yates R A, Montali R J. Canine distemper in terrestrial carnivores: a review. J Zoo Wild Med 2000; 31 (4): 441-51. doi: 10.1638/1042-7260(2000)031[0441:CDIT CA]2.0.CO;2.

77.- Thorne E T, Williams E S. Disease and endangered species: the black-footed ferret as a recent example. Conserv Biol 1988; 2: 66-74. doi: 10.1111/j.1523-1739.1988. tb00336.x.

78.- Acosta-Jamett G, Surot D, Cortés M, Marambio V, Valenzuela C, Vallverdu A, et al. Epidemiology of canine distemper and canine parvovirus in domestic dogs in urban and rural areas of the Araucanía region in Chile. Vet Microbiol 2015b; 178 (3): 260-4. doi: 10.1016/j.vetmic.2015.05.012.

79.- Acosta-Jamett G, Chalmers W S K, Cunningham A A, Cleaveland S, Handel I G. Urban domestic dog populations as a source of canine distemper virus for wild carnivores in the Coquimbo region of Chile. Vet Microbiol 2011; 152 (3): 247-57. doi: 10.1016/j. vetmic.2011.05.008

80.- Rubio A V, Fredes F, Bonacic C. Serological and parasitological survey of free-ranging Culpeo Foxes (Lycalopex culpaeus) in the Mediterranean biodiversity hotspot of central Chile. J Anim Vet Adv 2013; 12 (18): 1445-9. doi: 10.3923/javaa.2013.1445.1449.

81.- González-Acuña D, Ortega-Vásquez R, Rivera-Ramírez P, Cabello-Cabalin J. Verdacht auf Staupe beim Graufuchs (Pseudalopex griseus) im mittleren Chile (Fallbericht). Z Jagdwiss 2003; 49 (4): 323-6. doi: 10.4067/ S0301-732X2012000100014.

82.- Jiménez J E, Briceño C, Alcaíno H, Vásquez P, Funk S, González-Acuña D. Coprologic survey of endoparasites from Darwin's fox (Pseudalopex fulvipes) in Chiloé,
Chile. Arch Med Vet 2012; 44 (1): 93-7. doi: 10.1007/BF02189641.

83.- Steinel A, Parrish C R, Bloom M E, Truyen U. Parvovirus infections in wild carnivores. J Wild Dis 2001; 37 (3): 594-607. doi: 10.7589/00903558-37.3.594.

84.- Berríos P. Antecedentes en Chile de enfermedades virales de los animales domésticos. II. Enfermedades de presentación cíclica y de alta seroprevalencia. Avances en Ciencias Veterinarias 2002; 17 (1-2): 1-12. doi: 10.5354/0719-5273.2010.9211.

85.- Mora M, Napolitano C, Ortega R, Poulin E, Pizarro-Lucero J. Feline immunodeficiency virus and feline leukemia virus infection in free-ranging guignas (Leopardus guigna) and sympatric domestic cats in human perturbed landscapes on Chiloé Island, Chile. J Wild Dis 2015; 51 (1): 199-208. doi: 10.7589/2014-04114.

86.- Silva-Rodríguez E A, Ortega-Solís G R, Jiménez J E. Human attitudes toward wild felids in a human-dominated landscape of southern Chile. Cat News 2007; 46 : 19-21. https://chile.unt.edu/sites/chile. unt.edu/files/catalogue/pdf/55\%20 Silva-Rodr\%C3\%ADguez\%20etal\%20 HumanAttitudesFelids\%202007\%20CatNews. pdf.

87.- Lee J S, Bevins S N, Serieys L E K, Vickers W, Logan K A, Aldredge M, et al. Evolution of puma lentivirus in bobcats (Lynx rufus) and mountain lions (Puma concolor) in North America. J Virol 2014; 88 (14): 7727-37. DOI: $10.1128 / J V I .00473-14$.

88.- Pizarro-Lucero J, Celedón M O, Navarro C, Ortega R, González D. Identification of a pestivirus isolated from a free-ranging pudu (Pudu puda) in Chile. Vet Rec 2005; 157(10): 292-4. PMID: 16157573.

89.- Corti P, Saucedo C, Herrera P. Evidence of bovine viral diarrhea, but absence of infectious bovine rhinotracheitis and bovine brucellosis in the endangered huemul deer (Hippocamelus bisulcus) in Chilean Patagonia. J Wild Dis 2013; 49 (3): 744-6. DOI: 10.7589/2012-04105.

90.- Van Bressem M F, Reyes J C, Félix F, Echegaray M, Siciliano S, Di Beneditto A P, et al. A preliminary overview of skin and skeletal diseases and traumata in small cetaceans from South American waters. LAJAM Latin Amer J Aquatic Mammals 2007; 6 (1): 7-42. doi: 10.5597/lajam00108.

91.- Van Bressem M F, Van Waerebeek K, Aznar F J, Raga J A, Jepson P D, Duignan P, et al. Epidemiological pattern of tattoo skin disease: a potential general health indicator for cetaceans. Dis Aquat Organ 2009; 85 (3): 225 37. doi: 10.3354/dao02080.

92.- Van Bressem M F, Van Waerebeek K, Fleming M, Barrett T. Serological evidence of morbillivirus infection in small cetaceans from the Southeast Pacific. Vet Microb 1998; 59: 89-98. PMID: 9549850.

93.- Van Bressem M F, Van Waerebeek K, Raga J A, Godfroid J, Brew S D. Serologic evidence of Brucella infection in odontocetes from the south Pacific and the Mediterranean. Vet Rec 2001; 148: 657-61. PMID: 11400986.

94.- Van Bressem M F, Duignan P J, Banyard A, Barbieri M, Colegrove K M, De Guise S et al. Cetacean morbillivirus: current knowledge and future directions. Viruses 2014; 6 (12): 5145 81. doi: 10.3390/v6125145.

95.- Guglielmone A A, Robbins R G, Apanaskevich D A, Petney T N, Estrada-Peña A, Hprak I, et al. The Argasidae, Ixodidae and Nuttalliellidae (Acari: Ixodida) of the world: a list of valid species names. Zootaxa 2010; 2528: 1-28. doi: 10.1007/978-94-017-3526-1_2.

96.- Abarca K, López J, Perret C, Guerrero J, Godoy P, Veloz A, et al. Anaplasma platys in dogs, Chile. Emerg Infect Dis 2007; 13 (9): 1392-5. doi: 10.3201/eid1309.070021.

97.- López J, Abarca K, Mundaca M A, Caballero C, Valiente-Echeverría F. Identificación molecular de Ehrlichia canis en un canino de la ciudad de Arica, Chile. Rev Chilena Infectol 2012; 29 (5): 527-30. doi: 10.4067/S0716- 10182012000600008.

98.- Abarca K, López J, Acosta-Jamett G, Martínez-Valdebenito C. Identificación de Rickettsia andeanae en dos regiones de Chile. Rev Chilena Infectol 2013; 30 (4): 388-94. doi: 10.4067/S0716- 10182013000400006.

99.- Abarca K, López J, Acosta-Jamett G, Martínez-Valdebenito C. Rickettsia felis in Rhipicephalus sanguineus from two distant Chilean cities. Vector Borne Zoonotic Dis 2013b; 13 (8): 607-9. doi: 10.1089/ vbz.2012.1201

100.- Müller A, Monti G, Otth C, Sepúlveda P, Bittencourt P, Nachum-Biala Y, et al. "Candidatus Neoehrlichia chilensis" sp. nov.: Molecular detection and characterization of a novel Anaplasmataceae in wild rodents from Valdivia, southern Chile. Transbound Emerg Dis 2018; 65 (2): 357-62. doi: 10.1111/tbed.12815.

101.- Pérez G G, Torres J, Santos F S, Martino S, Velazquez E, Ramón G. Borrelia burgdorferi infection and cutaneous Lyme disease, México. Emerg Infect Dis 2007; 13 (10): 1556-8. doi: 10.3201/eid1310.060630.

102.- Ivanova L B, Tomova A, González-Acuña D, Murúa R, Moreno C X, Hernández C, et al. Borrelia chilensis, a new member of the Borrelia burgdorferi sensu lato complex that extends the range of this genospecies in the Southern Hemisphere. Env Microbiol 2014; 16 (4): 1069-80. doi: 10.1111/1462-2920.12310.

103.- Verdugo C, Jiménez O, Hernández C, Álvarez P, Espinoza A, González-Acuña D. Infection with Borrelia chilensis in Ixodes stilesi ticks 
collected from Pudu puda deer. Ticks Tick Borne Dis 2017; 8 (5): 733-40. doi: 10.1016/j. ttbdis.2017.05.00.

104.- Bengis R G, Kock R A, Fischer J. Infectious animal diseases: the wildlife/livestock interface. Rev Sci Tech 2002; 21 (1): 53-65. PMID: 1197463.

105.- Rhyan J C, Spraker T R. Emergence of diseases from wildlife reservoirs. Vet Pathol 2010; 47 (1): 34-9. doi: $10.1177 / 0300985809354466$.

106.- Povilitis A. Characteristics and conservation of a fragmented population of huemul Hippocamelus bisulcus in central Chile. Biol Conserv 1998; 86 (1): 97-104. doi: 10.1016/ S0006-3207(97)00161-4.

107.- Morales N, Aldridge D, Bahamonde A, Cerda J, Araya C, Muñoz R, et al. Corynebacterium pseudotuberculosis Infection in Patagonian Huemul (Hippocamelus bisulcus). J Wild Dis 2017; 53 (3): 621-4. doi: 10.7589/2016-09-213.

108.- Young J K, Olson K A, Reading R P, Amgalanbaatar S, Berger J. Is wildlife going to the dogs? Impacts of feral and free-roaming dogs on wildlife populations. BioScience 2011; 61 (2): 125-32. doi: 10.1525/ bio.2011.61.2.7.

109.- Mamaev L V, Denikina N N, Belikov S I, Volchkov V E, Visser I K G, et al. Characterisation of morbilliviruses isolated from Lake Baikal seals (Phoca sibirica). Vet Microbiol 1995; 44 (2-4): 251-9. doi: 10.1016/0378-1135(95)00018-6.

110.- Silva R F, Riedemann S. Seroprevalencia de leptospirosis canina en perros atendidos en clínicas veterinarias, mediante aglutinación microscópica y comparación con las técnicas de aislamiento e inmunofluorescencia indirecta. Arch Med Vet 2007; 39 (3): 269-74. doi: 10.4067/S0301- 732X2007000300011.

111.- Núñez F, Favi M, Urcelay V, Sepúlveda C,
Fabrega F. Rabia silvestre en murciélagos insectívoros en Chile. Bol Of Sanit Panam 1987; 103 (2): 140-5. http://iris.paho.org/ xmlui/bitstream/handle/123456789/18008/ v103n2p140.pdf? sequence=1.

112.- Favi M, Yung V, Pavletic C, Ramírez E, De Mattos C, De Mattos C A. Rol de los murciélagos insectívoros en la transmisión de la rabia en Chile. Arch Med Vet 1999; 31 (2): 157-65. doi: 10.4067/S0301732X1999000200002.

113.- Yung V, Favi M, Fernández J. Genetic and antigenic typing of rabies virus in Chile. Arch Virol 2002; 147 (11): 2197-205. doi: 10.1007/ s00705-002-0894-3.

114.- Cabello J, Esperon F, Napolitano C, Hidalgo E, Dávila J A, Millán J. Molecular identification of a novel gammaherpesvirus in the endangered Darwin's fox (Lycalopex fulvipes). J Gen Virol 2013; 94 (12): 2745-9. doi: 10.1099/vir.0.057851-0.

115.- Castelli M. Investigaciones sobre la existencia de leptospiras y leptospirosis en Chile. Bol Inst Bacteriol Chil 1959; 11: 5-31.

116.- Muñoz-Zanzi C, Mason M, Encina C, González M, Berg S. Household characteristics associated with Rodent presence and Leptospira infection in rural and urban communities from South Chile. Am J Trop Med Hyg 2014; 90 (3): 497-506. doi: 10.4269/ ajtmh.13-0334.

117.- Zamora J, Alonso O, Chahuan E. Isolement et caractérisation de Yersinia enterocolitica chez les rongeurs sauvages du Chili. Zentralbl Veterinarmed B 1979; 26 (5): 392-6. PMID: 532480.

118.- Cabello J, Altet L, Napolitano C, Sastre N, Hidalgo E, Dávila J A, et al. Survey of infectious agents in the endangered Darwin's fox (Lycalopex fulvipes): High prevalence and diversity of hemotrophic mycoplasmas. Vet Microbiol 2013; 167 (3): 448-54. doi: 10.1016/j.vetmic.2013.09.034.

119.- Sturm N, Abalos P, Fernández A, Rodríguez G, Oviedo P, Arroyo V, Retamal P. Salmonella enterica in pinnipeds, Chile. Emerg Infect Dis 2011; 17 (12): 2377-8. doi: 10.3201/ eid1712.111103.

120.- Toro M, Retamal P, Allard M, Brown EW, Evans P, Gonzalez-Escalona N. Draft genome sequences of 33 Salmonella enterica clinical and wildlife isolates from Chile. Genome Announc 2015; 3(2): e00054-15. doi: 10.1128/ genomeA.00054-15.

121.- Salinas P, Moraga R, Santander E, Sielfeld W. Presencia de cepas diarreogénicas de Escherichia coli y estudio de genes de virulencia en aislados desde fecas de dos poblaciones de lobo marino común, Otaria flavescens en el norte de Chile. Rev Biol Mar Oceanogr 2010; 45 (1): 153-8. doi: 10.4067/ S0718- 19572010000100016.

122.- González M, Villanueva M P, Debruyne L, Vandamme P, Fernández H. Campylobacter insulaenigrae: first isolation report from South American sea lion Otaria flavescens (Shaw, 1800). Braz J Microbiol 2011; 42 (1): 261-5. doi: 10.1590/S151783822011000100033 .

123.- González-Fuentes M, Latif F, Fernández F, Villanueva M P, Ulloa J, Fernández H. Especies de la familia Enterobacteriaceae en heces de lobo marino común, Otaria flavescens establecido en el río Valdivia. Rev Biol Mar Oceanogr 2010; 45 (2): 331-4. doi: 10.4067/ S0718-19572010000200015.

124.- Mathieu X, Durán J C, Rivas R M. Estudio de la flora bacteriana normal de Chinchilla lanigera silvestre. Rev Latinoam Microbiol 1982; 24: 77-82. PMID: 7186674. 